\title{
əAn Initiation Process of Tropical Depression-Type Disturbances under the Influence of Upper-Level Troughs 0
}

\author{
YUYA HAMAGUCHI ${ }^{\mathrm{a}}$ AND YUKARI N. TAKAYABU ${ }^{\mathrm{a}}$ \\ a Atmosphere and Ocean Research Institute, The University of Tokyo, Kashiwa, Chiba, Japan
}

(Manuscript received 3 November 2020, in final form 20 August 2021)

\begin{abstract}
In this study, the statistical relationship between tropical upper-tropospheric troughs (TUTTs) and the initiation of summertime tropical depression-type disturbances (TDDs) over the western and central North Pacific is investigated. By applying a spatiotemporal filter to the 34-yr record of brightness temperature and using JRA-55 products, TDDevent initiations are detected and classified as trough-related (TR) or non-trough-related (non-TR). The conventional understanding is that TDDs originate primarily in the lower troposphere; our results refine this view by revealing that approximately $30 \%$ of TDDs in the $10^{\circ}-20^{\circ} \mathrm{N}$ latitude ranges are generated under the influence of TUTTs. Lead-lag composite analysis of both TR- and non-TR-TDDs clarifies that TR-TDDs occur under relatively dry and less convergent large-scale conditions in the lower troposphere. This result suggests that TR-TDDs can form in a relatively unfavorable low-level environment. The three-dimensional structure of the wave activity flux reveals southward and downward propagation of wave energy in the upper troposphere that converges at the midtroposphere around the region where TR-TDDs occur, suggesting the existence of extratropical forcing. Further, the role of dynamic forcing associated with the TUTT on the TR-TDD initiation is analyzed using the quasigeostrophic omega equation. The result reveals that moistening in the mid- to upper troposphere takes place in association with the sustained dynamical ascent at the southeast side of the TUTT, which precedes the occurrence of deep convective heating. Along with a higher convective available potential energy due to the destabilizing effect of TUTTs, the moistening in the mid- to upper troposphere also helps to prepare the environment favorable to TDDs initiation.
\end{abstract}

KEYWORDS: Tropics; Deep convection; Wave breaking; Synoptic-scale processes; Upper troposphere; Statistics

\section{Introduction}

Tropical depression (TD)-type disturbances (hereafter, TDDs) are synoptic-scale disturbances traveling westward or northwestward over the North Pacific and the Atlantic Ocean (Takayabu and Nitta 1993; Galarneau et al. 2015) and are most active during the boreal summer. As preceding studies suggested, many western Pacific tropical cyclones (TCs) form in association with TDDs (Briegel and Frank 1997; Ritchie and Holland 1999). Despite their importance in tropical cyclogenesis, the initiation process of TDDs is not fully understood.

TDDs are recognized as well-coupled disturbances of lowlevel cyclonic circulation featuring convection (e.g., Lau and Lau 1990) and are assumed to originate in the lower troposphere. As documented by Kiladis et al. (2009), many studies (Holland 1995; Sobel and Bretherton 1999; Kuo et al. 2001; Dickinson and Molinari 2002; Li et al. 2003) have shown that

DDenotes content that is immediately available upon publication as open access.

Supplemental information related to this paper is available at the Journals Online website: https://doi.org/10.1175/JAS-D-200334.s1. ac.jp wave energy accumulation associated with the convergence of low-level zonal winds is a key to the initiation of TDDs over the western Pacific. Local sources of wave activity include preexisting TCs as well as synoptic-scale disturbances (Sobel and Bretherton 1999; Kuo et al. 2001; Li et al. 2003; Chen and Tam 2012), and short equatorial waves such as mixed Rossby-gravity (MRG) waves (Takayabu and Nitta 1993; Dickinson and Molinari 2002; Aiyyer and Molinari 2003). Other suggestions for initiation processes of TDDs include instabilities in the low-level summertime mean flow (e.g., Nitta and Yanai 1969; Li 2006).

In contrast to these studies, some other studies (e.g., Riehl 1948; Sadler 1976, 1978; Shimamura 1982; Heta 1991; Tam and Li 2006; Galarneau et al. 2015; Feng et al. 2016) have focused on "upper-origin" TDDs that occur under the influence of tropical upper-tropospheric troughs (TUTTs). As referenced in Galarneau et al. (2015), Riehl (1948) and Sadler (1976, 1978) investigated the contribution of TUTTs and upper-level cutoff lows (referred to as TUTT cells) to TC development. They found that TUTTs and TUTT cells encourage TC development by enhancing near-surface convergence and upper-level divergent outflow on their southeastern flanks. Shimamura (1982) and Heta (1991) provided observational evidence that some TDD-initiation events near the central Pacific at around $\sim 20^{\circ} \mathrm{N}$ are associated with TUTTs. These TUTTs occur as part of the upper-level mid-Pacific trough (Ramage 1959) and move westward. Further, Tam and Li (2006) found a linkage between TDDs and southward- and downward-propagating upper-level wave 
activities associated with the upper-level Rossby waves from the extratropics. Their case study also suggests that the extratropical forcing can act as a cause of TDD occurrence. Although these studies explained the relationship between trough-related TDDs (TR-TDDs) and the large-scale circulation, statistical characteristics of TR-TDDs in terms of spatial distribution, occurrence frequency, and environmental features-particularly with respect to moisture-are not fully understood.

The goal of this study is to reveal the initiation process of TR-TDDs in a statistical manner. For this purpose, initiation events of TDDs during the boreal summer over the North Pacific are detected and classified as either TR-TDDs or nontrough-related (NTR-) TDDs, and lead-lag composite analyses are performed to compare their characteristics statistically. Further, this study examines the initiation processes of TRTDDs, focusing on the effects of dynamical forcing, changes in the environmental moisture, and the destabilization due to the upper-level trough.

The rest of this paper is organized as follows. Section 2 describes the datasets and the methodology used in this study. Section 3 compares the observed statistical characteristics of TDDs with and without the influences of TUTTs. In section 4, we focus on the roles of TUTTs in the initiation of TDDs, and a detailed discussion is presented in section 5. Finally, section 6 presents a summary and conclusions.

\section{Data and methodology}

\section{a. Datasets}

\section{1) MERGED CLAUS-IR}

In this study, the merged CLAUS-IR dataset (Dias et al. 2017) is used as a long-term record of high-resolution brightness temperature $\left(T_{b}\right)$ data. The dataset comprises the Cloud Archive User Service (CLAUS) dataset (Hodges et al. 2000) and globally merged infrared radiation (IR) datasets (Janowiak et al. 2001). The estimated $T_{b}$ is provided from 1 July 1983 through 31 December 2017 at a 3-hourly resolution on $0.5^{\circ} \times 0.5^{\circ}$ horizontal grids. The analysis period for this study is from June to August 1984-2017.

\section{2) JRA-55}

To classify all TDD-initiation events as either TR-TDDs or NTR-TDDs and investigate their statistical features, the Japanese 55-year Reanalysis (JRA-55) data produced by the Japan Meteorological Agency (Kobayashi et al. 2015) are used. The time resolution of JRA-55 is 6-hourly, and the horizontal grid interval is $1.25^{\circ} \times 1.25^{\circ}$ in both longitude and latitude.

\section{3) $\mathrm{SSM} / \mathrm{I}$}

Six-hourly precipitable water estimates from the Special Sensor Microwave Imager (SSM/I) (Wentz et al. 2012), equipped on the U.S. Air Force Defense Meteorological Satellite Program (DMSP) spacecraft since 1987, are used to study differences of moisture fields between TR-TDDs and NTR-TDDs. The horizontal resolution is $0.25^{\circ} \times 0.25^{\circ}$ in longitude and latitude.

\section{b. Detection methods of TR-TDDs and NTR-TDDs}

We use the wavenumber-frequency filtering method to extract TDD signals from the CLAUS-IR brightness temperature field. The calculation procedure is similar to those used in Wheeler and Kiladis (1999), although the analysis domain is limited to the tropical North Pacific (defined as longitudes of $90^{\circ} \mathrm{E}-120^{\circ} \mathrm{W}$ ). The wavenumber-frequency spectra of $T_{b}$, averaged over the latitudes of $0^{\circ}-20^{\circ} \mathrm{N}$ over 34 years, are shown in Fig. 1. Figures $1 \mathrm{a}$ and $1 \mathrm{~b}$ show the spectral powers for the equatorially symmetric and antisymmetric components, respectively, divided by the background power shown in Fig. 1c. The major peaks of convectively coupled equatorial waves and westward-propagating synoptic-scale signals of TDDs are well captured in Figs. $1 \mathrm{a}$ and $1 \mathrm{~b}$. In this study, the 2.5-12-day bandpass-filtered westward-traveling $T_{b}$ signals (shown as blue dotted boxes in Figs. 1a,b) are used to represent the convective activity of TDDs. Although the TDD and MRG wave signals cannot be separated clearly in Fig. 1b, the
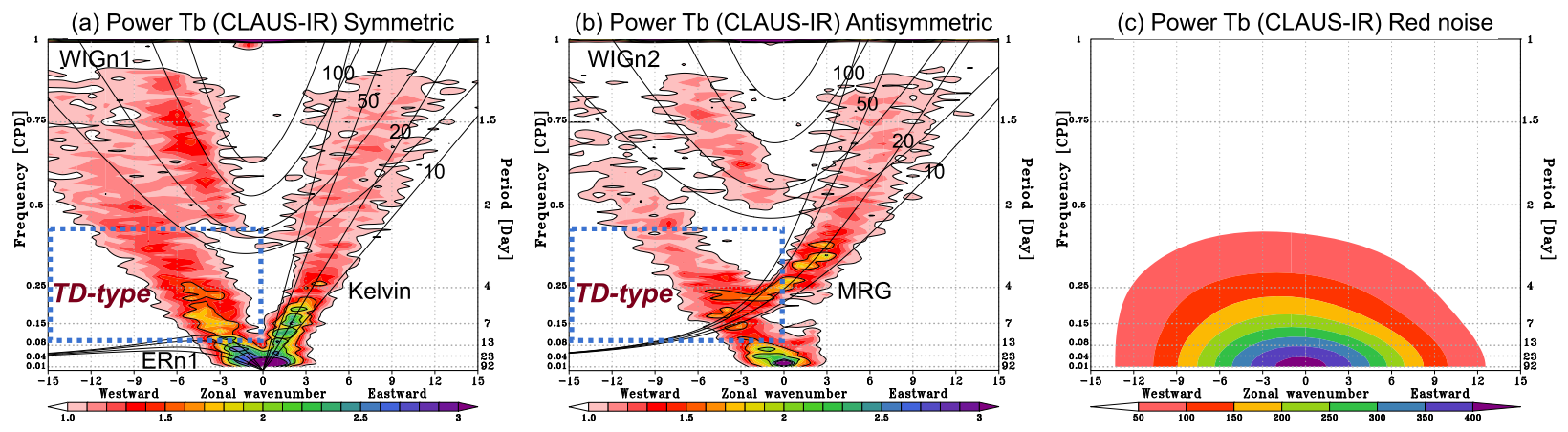

FIG. 1. Power spectra of (a) symmetric and (b) antisymmetric components of $T_{b}$ divided by the (c) background power, over the longitude range of $90^{\circ}-240^{\circ} \mathrm{E}$. The spectra are averaged over the latitude range of $0^{\circ}-20^{\circ} \mathrm{N}$ from June to August $1984-2017$. Contour interval is 0.5 , and colors begin at a value of 1.0 for which the spectral signatures are statistically above the background at the $99 \%$ level (based on 16470 degrees of freedom for the red noise). Dispersion curves of equatorial waves are also plotted for equivalent depths of $h=10,20,50$, and $100 \mathrm{~m}$. 
MRG waves peak primarily in the lower latitudes (not shown), an area of no particular interest in this study (discussed later). The selection of period range for the bandpass filtering follows the previous studies (e.g., Maloney and Dickinson 2003), and the results are not sensitive to its selection (not shown).

Next, we define TR-TDDs as TDDs initiated under an influence of the TUTT, a system that accompanies the intrusion of northern high potential vorticity (PV) air into tropical latitudes, in accordance with "PV thinking" (Hoskins et al. 1985). The meridionally reversed PV gradient configuration at the tropopause, or tropopause folding, exemplifies the interaction between the troposphere and stratosphere (e.g., Andrews et al. 1987). As shown by Liniger and Davies (2004, see their Fig. 1) the $360-\mathrm{K}$ isentropic surface lies just below the dynamical tropopause (defined by $2.0 \mathrm{PV}$ unit surface ( $1 \mathrm{PVU}=10^{-6}$ $\mathrm{K} \mathrm{kg}^{-1} \mathrm{~m}^{2} \mathrm{~s}^{-1}$ ), following Holton et al. 1995) in the latitude range of $10^{\circ}-20^{\circ} \mathrm{N}$, in which TR-TDDs are found to occur frequently (Tam and Li 2006; Feng et al. 2016). Therefore, using $\mathrm{PV}$ values greater than 2.0 PV units on the $360-\mathrm{K}$ isentropic surface appears to serve as a good indicator of PV intrusion and the resultant extension of TUTTs to $10^{\circ}-20^{\circ} \mathrm{N}$.

Examples of extracted TDD signals are shown in Hovmöller diagrams in Fig. 2. Here, TDDs are identified with negative-value perturbations of the filtered $T_{b}$ with black contours. For instance, a TR-TDD in the dashed curve A occurs without a clear low-level vortex (Fig. 2b); instead, its initiation is associated with anomalous southerly winds of upper-level cyclonic circulation (Fig. 2a), which has a large positive PV value around the tropopause (Fig. 2c). These configurations indicate a possible contribution of upper-level circulation to the initiation of the TR-TDD. In contrast, the TDDs in the dashed curves $\mathrm{B}$ and $\mathrm{C}$ start with a distinct cyclonic circulation in the lower troposphere (Fig. 2b) and are not in association with high PV values around the tropopause (Fig. 2c).

To better differentiate TR- and NTR-TDD initiations in an objective manner, we perform TDD detection and classification. After adjusting the grid spacing of the filtered $T_{b}$ signal to that of the JRA-55 6-hourly products, all TDD-initiation events over the tropical North Pacific during the overall data period (from June to August 1984-2017) are examined.

\section{1) DEFINITION OF INITIATION TIME AND POINT OF TDDs}

First, the times and the locations of TDD-event initiations are identified using the entire analysis region $\left(0^{\circ}-30^{\circ} \mathrm{N}, 90^{\circ} \mathrm{E}-120^{\circ} \mathrm{W}\right)$. Figure 3 a shows a schematic for the detection of a TDD-event initiation. The time and the location of a TDD-event initiation are defined as follows, respectively.

D1: The timing at which the filtered $T_{b}$ reaches less than $-10 \mathrm{~K}$. (a) $v_{150 h P a}^{\prime}$

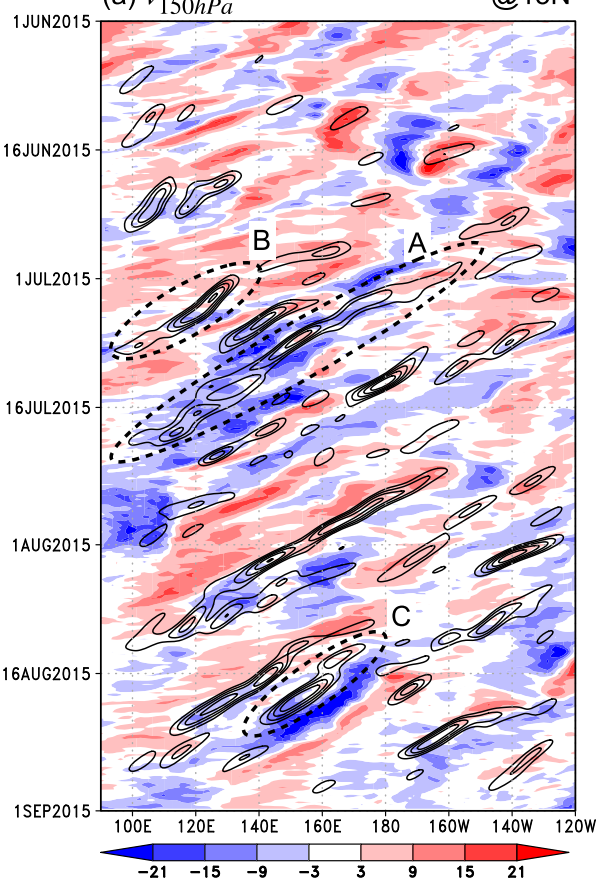

(b) $v_{850 h P a}^{\prime}$

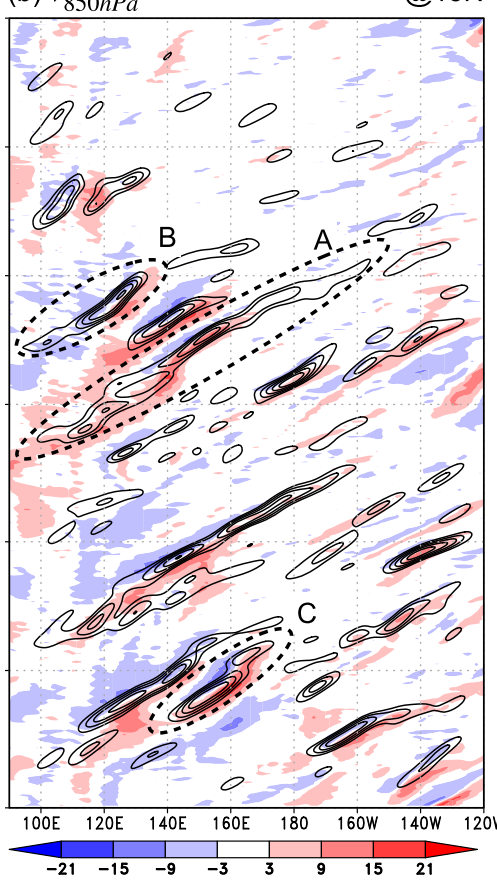

(c) PV@360K surface

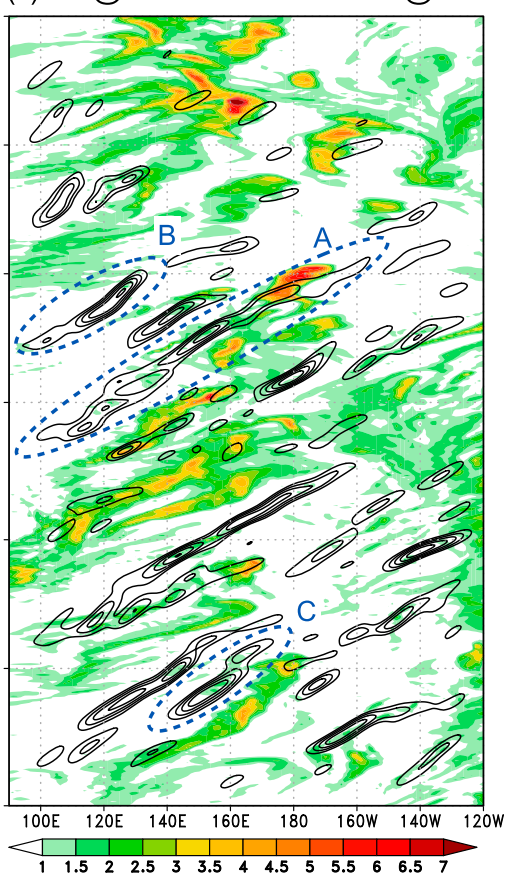

FIG. 2. Examples for TDD initiations shown in Hovmöller diagrams at $15^{\circ} \mathrm{N}$ from June to August 2015. Black contours in each panel indicate the filtered $T_{b}$. Contour interval is $-10 \mathrm{~K}$ with first contour at $-10 \mathrm{~K}$. Color shades in each panel show (a) the anomalous meridional wind at $150 \mathrm{hPa}\left(\mathrm{m} \mathrm{s}^{-1}\right)$, (b) as in (a), but at $850 \mathrm{hPa}$, and (c) potential vorticity on the $\theta=360-\mathrm{K}$ surface (PVU). Anomalies are defined as the differences from the seasonal mean at each grid. The perturbation of filtered $T_{b}$ in the dashed curve A in each panel depicts a TRTDD-initiation event, and the dashed curves B and C show examples of NTR-TDD-initiation events. 

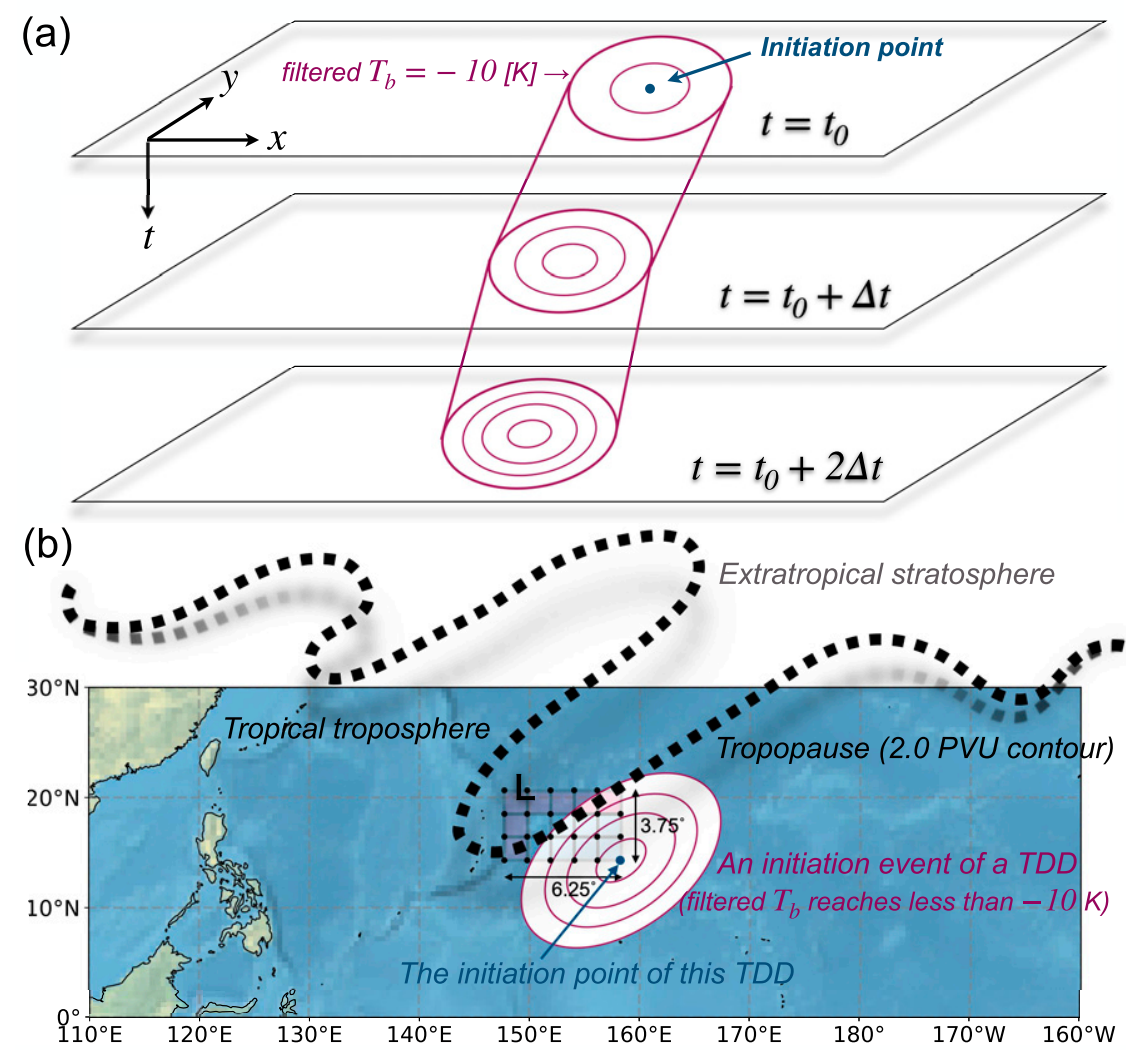

FIG. 3. Schematic representation of detection techniques for (a) the initiation point of TDDs and (b) TR-TDDs used in this study. In (a), a TDD is assumed to be initiated at $t=t_{0}$ based on D1. The area surrounded by the purple envelope is the region where the filtered $T_{b}$ is less than $-10 \mathrm{~K}$, which is here treated as a TDD. The blue dot represents the initiation point of the TDD (see D2). In (b), the thick short-dashed black curve denotes the dynamically defined tropopause. The letter "L" represents the position of the TUTT associated with the PV intrusion. Purple solid contours show the filtered $T_{b}$ with the first contour at $-10 \mathrm{~K}$. As in (a), the blue dot is chosen as the initiation point. The judgment of the existence of the TUTT's influence on the TDD initiation is performed on the black dots within the rectangular region. For more detailed information, see the text.

D2: The grid point where a spatial minimum of the filtered $T_{b}$ is observed at the above timing.

Note that we assume a TDD exists as long as the filtered $T_{b}$ is colder than $-10 \mathrm{~K}$.

\section{2) CRITERIA FOR CLASSIFICATION FOR TR-TDDS}

Then, each event is classified either as a TR-TDD or a NTR-TDD. If the event has at least one grid point within a rectangular area of $6.25^{\circ} \times 3.75^{\circ}$ northwest of the initiation point of the event, which satisfies following all three criteria, the event is labeled a TR-TDD. Otherwise, the event is labeled an NTR-TDD.

$\mathrm{C} 1$ : Filtered $T_{b}$ is less than $-10 \mathrm{~K}$.

$\mathrm{C} 2$ : $\mathrm{PV}$ value on the $360-\mathrm{K}$ isothermal surface is greater than 2.0 PV unit.

$\mathrm{C} 3$ : Anomalous meridional wind at $150 \mathrm{hPa}$ surface is positive $\left(v_{150 \mathrm{hPa}}^{\prime}>0\right)$.
Here, the anomaly is defined as the differences from the 34 years summertime (June-August) climatological mean at each grid point, and the reference domain size $\left(6.25^{\circ} \times 3.75^{\circ}\right)$ is determined based on the Rossby radius of the upper-level trough as in Galarneau et al. (2015). Note that the criterion C3 is applied to extract TR-TDDs at the east side of the upper-level trough. This is because the influence of the upperlevel trough to the east of the TDD initiation is considered unfavorable for TDD occurrence (Sadler 1976, 1978; Shimamura 1982).

Figure 3 b shows a schematic for the methodology to classify a TDD as a TR-TDD. In Fig. 3b, the meridionally reversed PV gradient configuration at the tropopause exemplifies the interaction between the tropical troposphere and the extratropical stratosphere. The resultant cyclonic circulation arising from this upper-level high-PV intrusion, called a TUTT in this study, is represented by the capital "L." The judgment of the existence of the TUTT's influence on the TDD initiation 
is performed on each grid point within the rectangular region based on the criteria $\mathrm{C} 1-\mathrm{C} 3$. As mentioned above, the PV value greater than $2.0 \mathrm{PV}$ units on the $360-\mathrm{K}$ isentropic surface is treated as the indicator of PV intrusion in this study (C2). Sensitivity of the threshold of PV value is discussed later in section $3 \mathrm{a}$.

\section{c. Vertical motion diagnosis formula}

As described in section 1, some previous studies have examined the influence of TUTTs and TUTT cells on TC developments over the western North Pacific (e.g., Riehl 1948; Sadler 1976, 1978). Kelly and Mock (1982) suggested that dynamically forced quasigeostrophic (QG) ascent at the southeast side of TUTT cells can be important in TC development via enhancing near-surface convergence and divergent outflow aloft at that region. Some other studies utilized the QG omega $(\omega)$ equation in investigating TC genesis, TC intensification, and tropical transition under the influence of TUTTs to focus on the dynamical effect of the upper-level disturbances (McTaggart-Cowan et al. 2008, 2013; Fischer et al. 2017; Chang et al. 2019). In section 4, based on these studies, we compare dynamically and diabatically driven ${ }^{1}$ ascent based on the QG $\omega$ equation to clarify the role of upper-level dynamical effects on the initiation of TR-TDDs. Examples of such separations are found in previous studies (e.g., Horinouchi and Hayashi 2017; Nie and Fan 2019; Yokoyama et al. 2020). We apply the Q-vector form of the QG $\omega$ equation (e.g., Holton 2004) as follows:

$$
\begin{aligned}
\sigma \nabla^{2} \omega_{\mathrm{QG}}+f_{0}^{2} \frac{\partial^{2} \omega_{\mathrm{QG}}}{\partial p^{2}}= & -2 \nabla \cdot \mathbf{Q}+f_{0} \beta \frac{\partial}{\partial p}\left(\frac{\partial \psi}{\partial x}\right) \\
& -\frac{\kappa}{p} \nabla^{2} J_{\mathrm{LH}}-\frac{\kappa}{p} \nabla^{2} J_{R},
\end{aligned}
$$

where

$$
\mathbf{Q}=f_{0}\left(\begin{array}{c}
-\psi_{x y} \psi_{x p}+\psi_{x x} \psi_{y p} \\
-\psi_{y y} \psi_{x p}+\psi_{x y} \psi_{y p}
\end{array}\right)=-\frac{R}{p}\left(\begin{array}{c}
-\phi_{x y} T_{x}+\phi_{x x} T_{y} \\
-\phi_{y y} T_{x}+\phi_{x y} T_{y}
\end{array}\right)
$$

$\sigma\left[\equiv-(R T / p) \partial_{p} 2 \ln \theta\right]$ in Eq. (1) is the dry static stability; and $p, T$, and $\theta$ are the pressure, temperature, and potential temperature, respectively; $R$ is the gas constant, and $\kappa$ is $R C_{p}^{-1}$, where $C_{p}$ is the specific heat at constant pressure; $\nabla$ indicates the horizontal gradient operator; and $\psi$ and $\phi$ are the QG streamfunction and geopotential height, respectively. The diabatic heating rate in Eq. (1) consists of a latent heating term $J_{\mathrm{LH}}\left(\equiv J_{\mathrm{Conv}}+J_{\mathrm{LSC}}\right)$ and a radiative heating term $J_{R}\left(\equiv J_{\mathrm{SW}}+\right.$ $\left.J_{\mathrm{LW}}\right)$. The latent heating term $J_{\mathrm{LH}}$ is estimated as the sum of the convective heating rate $\left(J_{\text {Conv }}\right)$ and the large-scale condensation heating rate $\left(J_{\mathrm{LSC}}\right)$, both obtained from the JRA55. The radiative heating term $\left(J_{R}\right)$ is estimated as the sum of the shortwave $\left(J_{\mathrm{SW}}\right)$ and the longwave $\left(J_{\mathrm{LW}}\right)$ radiative heating rate. The $\mathrm{Q}$ vector in Eq. (1) is defined from Eq. (2). The latitude of each TDD-initiation point is used as the reference latitude of the $\beta$ plane.
According to Eq. (1), the total QG ascent $\omega_{\mathrm{QG}}$ can be separated into the dynamically induced upwelling $\omega_{D}$, latent-heating-driven upwelling $\omega_{\mathrm{LH}}$, and a residual. The $\omega_{D}$ can be given as the sum of the convergence of the $\mathrm{Q}$ vector [the first term on the right-hand side in Eq. (1)] and the $\beta$ effect term [the second term on the right-hand side in Eq. (1)]; the latter is generally small for synoptic-scale motion (Holton 2004). The $\omega_{\mathrm{LH}}$ can be determined from the third term on the righthand side in Eq. (1), which represents the diabatically generated ascent associated with the latent heat of cumulus convection. Note that the influence of radiative heating [the fourth term on the right-hand side of Eq. (1)] is found to be negligible compared to the effects of the other terms (not shown). Accordingly, the results discussed in section 4 compare only dynamical and latent-heat-driven effects.

To clarify the role of upper-level dynamical effects on the initiation of TR-TDDs, a comparison is made between the dynamically and diabatically driven upwellings. To derive each associated set of pressure velocities, we iteratively solve Eq. (1) using the successive overrelaxation (SOR) method. The calculation is performed over the range $0^{\circ}-60^{\circ} \mathrm{N}$, $90^{\circ} \mathrm{E}-120^{\circ} \mathrm{W}$ in 27 layers between 975 and $70 \mathrm{hPa}$ with the boundary condition of $\omega=0$ set at each boundary. The acceleration parameter under the SOR method is set to a constant value of 1.9. Each pressure velocity is diagnosed independently using only the corresponding right-hand side terms of Eq. (1). Before calculating the $\mathrm{Q}$ vector, following preceding studies (Horinouchi and Hayashi 2017; Yokoyama et al. 2020), the geopotential height and temperature are smoothed using a 1-2-1 filter in both the longitude and latitude directions over a $5^{\circ} \times 5^{\circ}$ grid to remove variations on a scale smaller than that of the geostrophic motion. We also smooth the higher-order derivative terms of the diabatic heating rate (both $J_{\mathrm{LH}}$ and $J_{R}$ ) in the same manner.

\section{Statistical characteristics of TR-TDDs and NTR-TDDs}

\section{a. Spatial distribution and frequency of occurrences}

We first examine the spatial distribution and frequency of occurrence of TR-TDDs and NTR-TDDs during 34 years of boreal summers over the North Pacific. Figure 4 shows a frequency distribution map on a latitude-longitude grid for detected TR-TDDs and NTR-TDDs. The spatial distribution of TR-TDDs has its main peak at around $20^{\circ} \mathrm{N}$ near the date line, which corresponds to the region of the climatological TUTTs. The southward-extending feature of climatological upper-level PV is the result of frequent PV-intrusions from the extratropics to the tropical central Pacific (see Fig. 4 in Postel and Hitchman 1999); TUTTs are assumed to accompany such PV intrusions. By contrast, the NTR-TDDs occur more frequently than TR-TDDs at lower latitudes and their initiation sites are more diverse, suggesting that they consist of varied disturbances that originate through different processes. Their features will be discussed in section $3 \mathrm{~b}$.

Table 1 lists the counts and ratios of detected TDDs. It is revealed that approximately $30 \%$ of TDDs are generated 

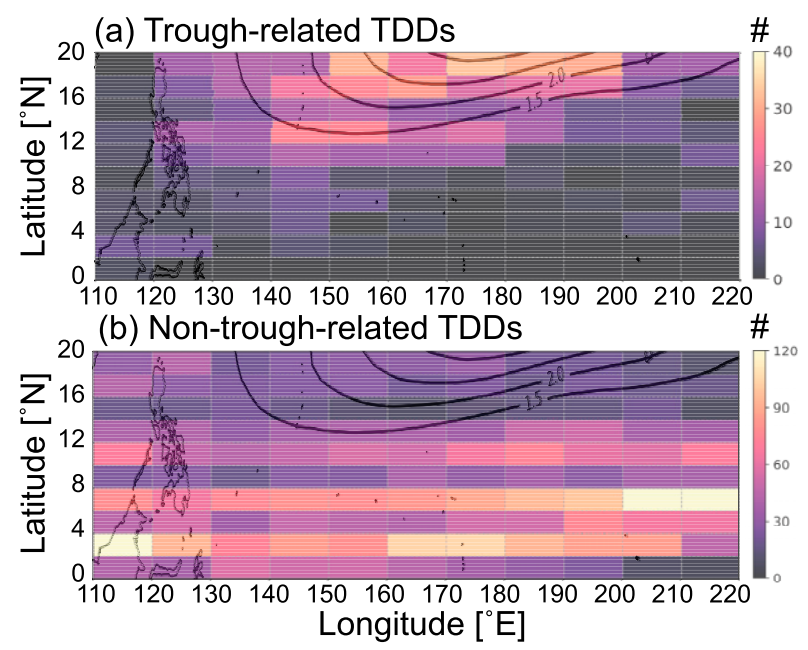

FIG. 4. (a) Horizontal distributions of the accumulated number of detected TR-TDD initiations over the North Pacific from June to August 1984-2017. Contours show the 34-yr boreal summer climatological value of potential vorticity on the $\theta=360-\mathrm{K}$ surface. The contour interval is 0.5 PVU with the first contour at 1.5 PVU. (b) As in (a), but for NTR-TDDs. Note that the color range in (b) is 3 times as large as that in (a).

under the influence of an upper-level trough in the region of $10^{\circ}-20^{\circ} \mathrm{N}$ (Table $1,2.0 \mathrm{PVU}$ ). The ratio of TR-TDDs to the total number of TDDs changes slightly with the PV threshold in $\mathrm{C} 2$, increasing (decreasing) by $6 \%-8 \%$ when the PV threshold is reduced (increased) by $0.5 \mathrm{PV}$ unit. If a smaller PV threshold is selected, the number of TR-TDD samples will increase but the TUTT amplitude and depth will be reduced. To better capture the relationship between upperlevel circulation and the initiation of lower-level disturbances, 2.0 PV units are applied as a moderate PV threshold for the composite analysis.
In the following section, we will investigate the environmental differences between TR- and NTR-TDD event initiations based on lead-lag composite analysis. To better visualize the differences between them, only disturbances occurring in the region of $10^{\circ}-20^{\circ} \mathrm{N}$ that maintained a minimum filtered $T_{b}$ smaller than $-10 \mathrm{~K}$ for at least 2 days are chosen as composite analysis targets. As a result, $334(28.8 \%$ of the total) and 827 (71.2\%) TR-TDDs and NTR-TDDs are chosen for the composite analysis, respectively. The spatial distributions and occurrence frequencies of the selected events do not differ significantly from Fig. 4 and Table 1.

\section{b. Environmental differences}

Figures 5a and 5b show horizontal patterns of the composited filtered $T_{b}$, PV on the $360-\mathrm{K}$ isentropic surface, and 10-day mean precipitable water associated with the initiation of TR-TDDs and NTR-TDDs. Both TR-TDDs and NTR-TDDs have negative filtered $T_{b}$ values, which indicates a convectively active area. Figure 5 a confirms that TUTTs denoted by upper-level high-PV values are accompanying TR-TDD initiations; by contrast, no significant TUTT signals are found in Fig. 5b for NTR-TDDs. In the TR-TDD cases, the values of precipitable water in the environment are smaller than those in the NTR-TDD cases by 3-4 mm, a result that is statistically significant at the $95 \%$ level based on the two-tailed Student's $t$ test. Note that the precipitable water is analyzed using 31 years of data, since the SSM/I products are only available from 1987. It is also notable that almost the same result is obtained when the precipitable water in the JRA-55 product is used, except that the overall value is slightly lower than that of SSM/I's (typically $\sim 2 \mathrm{~mm}$, not shown).

Similar comparisons for the lower-tropospheric horizontal divergence and relative vorticity are shown in Figs. 5c-f, respectively. Figures $5 \mathrm{c}$ and $5 \mathrm{~d}$ show that the TR-TDDs tend to be embedded in a less convergent low-level environment

TABLE 1. Statistics of the number of detected initiations of trough-related (TR) and non-trough-related (NTR) TDDs with their ratio to the total number. The results are categorized into two groups based on the latitude of the initiation point. Each row shows the case where the tropopause is defined as the 1.5, 2.0, and 2.5 PVU contours.

\begin{tabular}{lcccc}
\hline \hline & \multicolumn{2}{c}{ Trough-related (TR) } & \multicolumn{2}{c}{ Non-trough-related (NTR) } \\
Lat of initiation point & Number & Ratio (\%) & Number & Ratio (\%) \\
\hline $1.5 \mathrm{PVU}$ & & & & 63.6 \\
$10^{\circ}-20^{\circ} \mathrm{N}$ & 910 & 36.4 & 3155 & 91.9 \\
$0^{\circ}-10^{\circ} \mathrm{N}$ & 278 & 8.1 & & 71.8 \\
& & & & 96.7 \\
$2.0 \mathrm{PVU}$ & 703 & 28.2 & 3321 & \\
$10^{\circ}-20^{\circ} \mathrm{N}$ & 112 & 3.3 & & 78.1 \\
$0^{\circ}-10^{\circ} \mathrm{N}$ & & & 1952 & 98.7 \\
$2.5 \mathrm{PVU}$ & & & 3389 & \\
$10^{\circ}-20^{\circ} \mathrm{N}$ & 547 & 21.9 & & \\
$0^{\circ}-10^{\circ} \mathrm{N}$ & 44 & 1.3 & & \\
\hline
\end{tabular}

\footnotetext{
${ }^{1}$ We call the terms "dynamically driven" and "diabatically driven," as often called in recent papers. However, since the former term includes the effect of temperature advection, it might be better called as "large-scale driven."
} 


\section{Trough-related TDDs}

(a) Mean PW

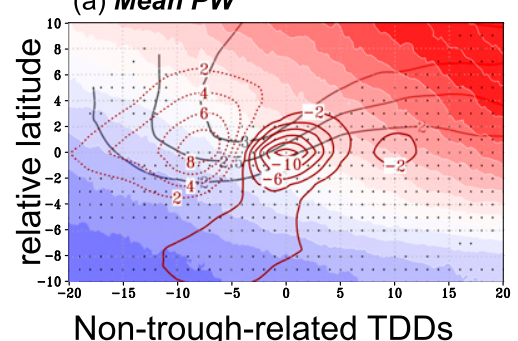

(b) Mean PW

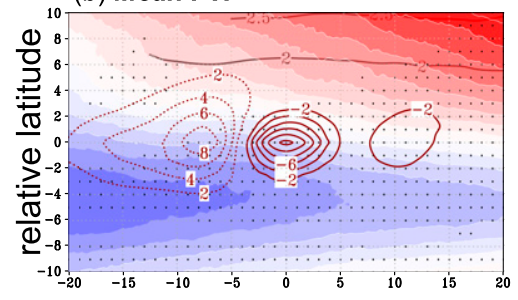

(c) Mean Divergence @850hPa

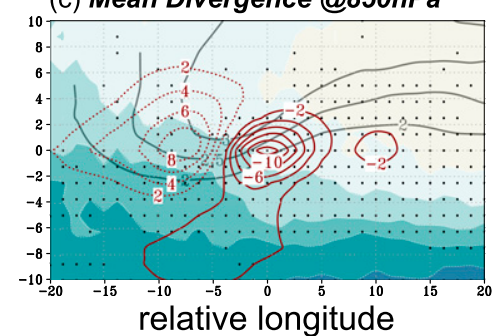

(d) Mean Divergence @850hPa

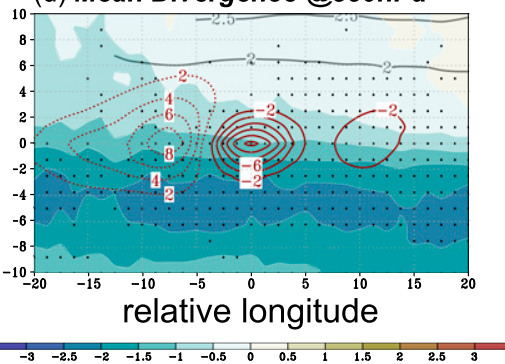

(e) Mean Relative Vorticity @850hPa

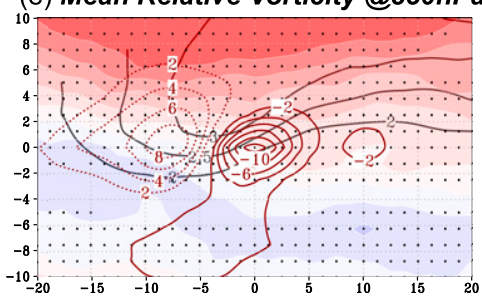

(f) Mean Relative Vorticity @850hPa

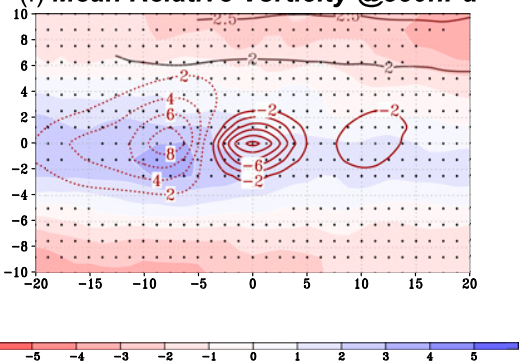

FIG. 5. (a) Horizontal patterns of lead-lag composites for TR-TDDs initiated in the $10^{\circ}-20^{\circ} \mathrm{N}$ region. The longitude and latitude are relative to the initiation point of each disturbance. Black contours show the value of potential vorticity on the $\theta=360-\mathrm{K}$ surface at day 0 , plotted only when the value is statistically above the climatological value at the $95 \%$ significance level. The contour interval is $0.5 \mathrm{PVU}$ with first contour at 2.0 PVU. Red contours indicate the filtered $T_{b}$ at day 0 with the interval of $2 \mathrm{~K}$. The dotted contours denote positive values, which mean convectively inactive. The zero contours are omitted. The color shades indicate the 10-day mean precipitable water (mm) retrieved from the SSM/I. (b) As in (a), but for NTR-TDDs. The black dots denote where the values of mean precipitable water in (a) and (b) show statistically significant difference at the 95\% level. (c)-(f) As in (a) and (b), but the color shades indicate (c),(d) the 10-day mean horizontal divergence at 850 -hPa surface and (e),(f) the 10-day mean relative vorticity at 850-hPa surface.

than the NTR-TDDs. The cyclonic vorticities of the environment are also seen to be significantly weaker in the TR-TDD cases (Figs. 5e,f). These environmental differences shown in Fig. 5 are partially attributable to the fact that the latitude at the disturbance center is higher in TR-TDD-cases than in NTR-TDD-cases (see Fig. 4). But this result can be confirmed by comparing the TR-TDDs and NTR-TDDs occurring at the same latitude (not shown), indicating that the effect of latitudinal reference point difference does not fully explain the differences in environmental features. Since previous studies suggest that both higher sea surface temperatures and more convergent background large-scale flows in the lower troposphere create favorable conditions for the genesis of tropical synoptic-scale disturbances (e.g., Tai and Ogura 1987; Kuo et al. 2001; Li 2006), the drier environment with less convergent ambient flow in the lower troposphere, found in the TRTDD-cases, indicates that TR-TDDs can occur within a relatively unfavorable condition compared to NTR-TDDs. Note that this study uses precipitable water instead of sea surface temperature, assuming that the pattern of precipitable water can represent that of sea surface temperature.

Despite under the relatively unfavorable environment, the magnitudes of anomalous precipitable water, relative vorticity, and horizontal divergence associated with TR-TDDs are almost comparable to those of NTR-TDDs (Figs. 6-8). It is hypothesized that the circulation associated with the TUTT helps TR-TDDs grow and organize, which results in the small differences between the strength of TR-TDDs and NTRTDDs (see day 1 of Fig. 7). The detailed mechanism and the role of TUTT in the TR-TDD initiation will be discussed in sections 4 and 5 .

Note that the NTR-TDDs in this study are defined as all TDDs which do not satisfy the classification criteria for TRTDDs. Thus, they are a mixture of various disturbances which occur in different ways. In the supplemental material, focusing on the differences in the environments, NTR-TDDs initiated in the western and the eastern North Pacific are distinguished, and their composites are shown separately. The western and the eastern NTR-TDDs are defined as those extracted from $110^{\circ}-165^{\circ} \mathrm{E}$ and $165^{\circ}-220^{\circ} \mathrm{E}\left(140^{\circ} \mathrm{W}\right)$, respectively. Figure S1 in the online supplemental material shows that the western NTR-TDDs are initiated in the monsoon trough region, where the environment is much wetter and has a larger lower-level convergence. The eastern NTR-TDDs, on the other hand, tend to occur at the northern edge of intertropical convergence zone (ITCZ). Figure S2 indicates that the low-level convergence associated with the western (eastern) NTR-TDDs mainly comes from the zonal (meridional) gradient of mean zonal (meridional) wind, which is the typical feature of monsoon trough (ITCZ) region. The moist environment with zonally convergent ambient flow in the western NTR-TDD cases implies that the wave energy accumulation is one of the causes of the western NTR-TDDs (Kuo et al. 2001). On the other hand, the wave energy accumulation is 
(a) Trough-related TDDs

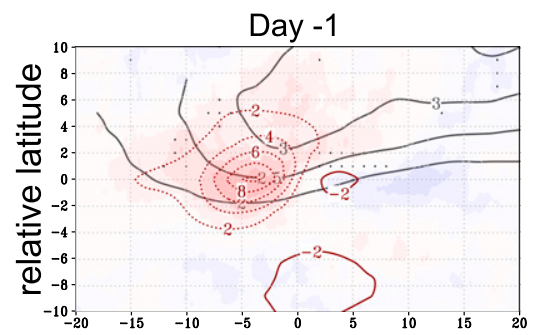

(b) Non-trough-related TDDs

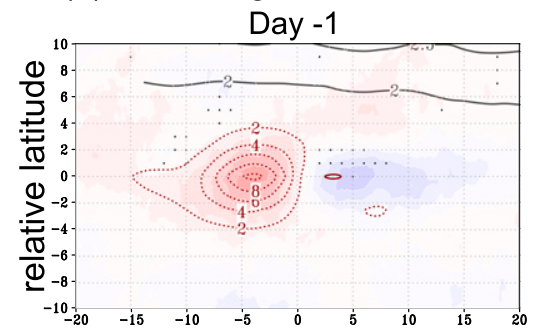

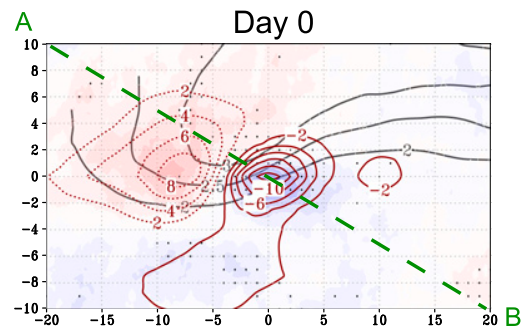

relative longitude

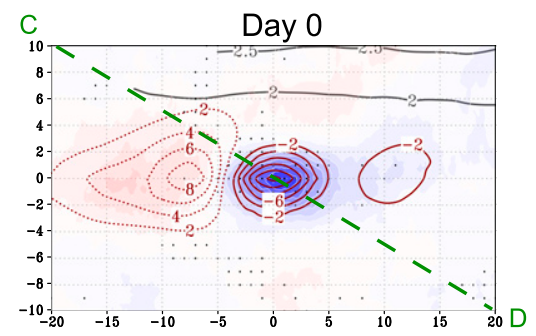

relative longitude
Precipitable Water'

Day 1

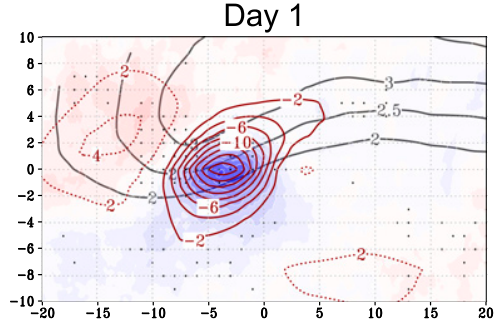

Day 1

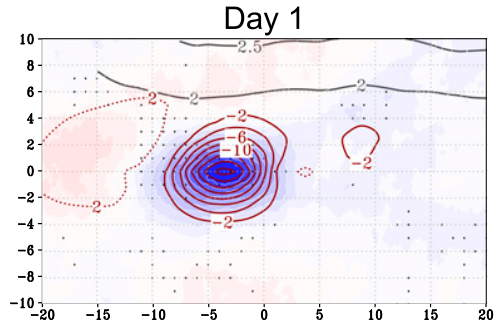

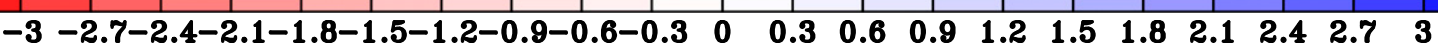

FIG. 6. (a) As in Fig. 5a, but the color shades indicate precipitable water anomalies from day -1 to day 1 . The anomalies are defined as the difference from the 10-day mean values. (b) As in (a), but for NTR-TDDs. The dashed lines from A to B in (a) and from C to D in (b) denote the cross sections taken for Fig. 12.

(a) Trough-related TDDs

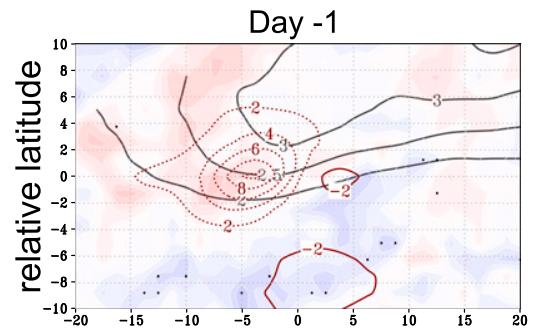

(b) Non-trough-related TDDs

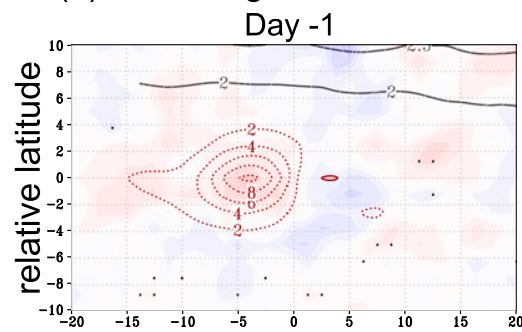

Day 0

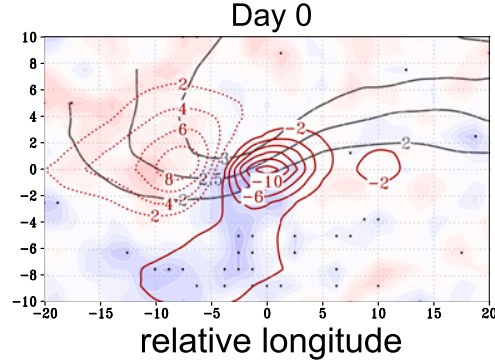

Day 0

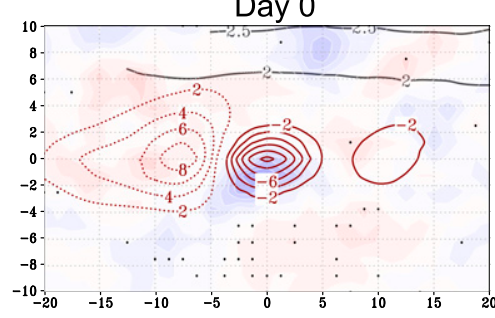

relative longitude

\section{Relative Vorticity’ @850hPa}

Day 1

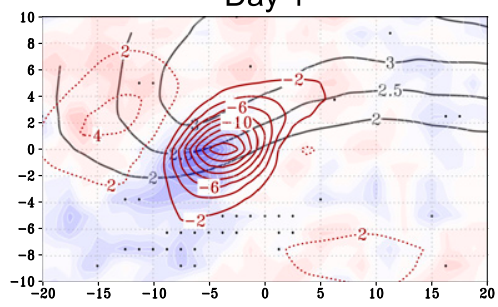

Day 1

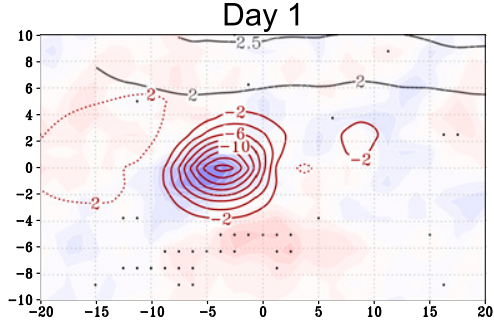

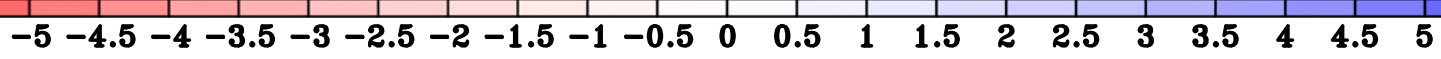

FIG. 7. As in Fig. 6, but the color shades indicate the composited relative vorticity anomalies at 850 -hPa surface $\left(10^{-6} \mathrm{~s}^{-1}\right)$. The black dots denote where the values of the relative vorticity show statistically significant differences at the $95 \%$ level. 
not likely to be attributable for the origin of the eastern NTRTDDs, since the zonal convergence is not seen in their cases. In the eastern NTR-TDD initiation, the barotropic and baroclinic instability of the ITCZ low-level jet, or ITCZ breakdown, is considered to play a role (Ferreira and Schubert 1997) to bear vorticity disturbances.

\section{c. Differences in vertical structures of disturbances}

As shown in Figs. 5-8, it is suggested that TUTTs play important roles in promoting the TR-TDD initiation. In sections 4 and 5 , the effect of the dynamical forcing and the destabilization due to the upper-level trough will be discussed. Here, we compare the vertical structure of TR-TDDs and NTR-TDDs before we discuss the plausible roles of TUTTs. As in the case study conducted by Tam and Li (2006), the vertical structure of TR-TDDs is expected to be very different from that of NTR-TDDs due to the presence of the upperlevel cold trough.

Figures 9 and 10 show time evolutions of the vertical structures for each type of disturbance along longitude-height cross sections at their initiation point latitudes. The upperlevel cyclonic circulations of the TUTTs reach the lower troposphere (Figs. 9a-c) accompanied by cold anomalies (Figs. 10a-c). By contrast, upper-level perturbations in the NTRTDD cases (Figs. 9d-f) are much weaker than those in the TR-TDD cases. The upper-level anomalous circulation in NTR-TDD cases is weakly anticyclonic and accompanied by a weak warm temperature anomaly (Figs. 10d-f).

Following initiation of the disturbances, the low-level vortices of the TR-TDDs vertically couple with the upperlevel vortices (Figs. 9b,c); in the NTR-TDD cases, by contrast, the upper-level vortices have opposite circulation (Figs. 9e,f). Although the vertical structure of the disturbance in the lower to midtroposphere appears to be nearly upright in both cases, a slight westward-tilting vorticity column is observed in the TR-TDD composite (e.g., Fig. 9c). Since TR-TDDs are embedded in a westerly sheared ambient flow (shown later in Fig. 11b), the westward tilt with height suggests an existence of baroclinic energy conversion.

The vertical structures of anomalous potential temperature and pressure velocity differ significantly between the TRTDD and NTR-TDD cases. The former contain the abovementioned cold anomalies over nearly the entire troposphere (Figs. 10a-c), while the latter feature weak warm anomalies in the upper troposphere sandwiched by weak cold anomalies above and below (Figs. 10d-f). The lower-level "cold cores" and upper-level warm anomalies in the NTR-TDD cases are well-known characteristics of tropical synoptic-scale disturbances (e.g., Chang et al. 1970; Lau and Lau 1990). Furthermore, in these cases the maxima of warm anomalies and minima of pressure velocity are well collocated (Figs. 10d-f), a result consistent with the known importance to the energetics of TDDs of the conversion from perturbation available potential energy, which is generated by diabatic heating, to kinetic energy (Lau and Lau 1992).

In either case, the pressure velocity has two peaks at lower $(750 \mathrm{hPa})$ and at upper $(300 \mathrm{hPa})$ levels. Interestingly, however, the evolution of the upper-level peak appear to differ between the two cases. For the NTR-TDD cases, the anomalous upward velocity starts from the near-surface and extends to the upper troposphere as the disturbance grows (Figs.

\section{(a) Trough-related TDDs}

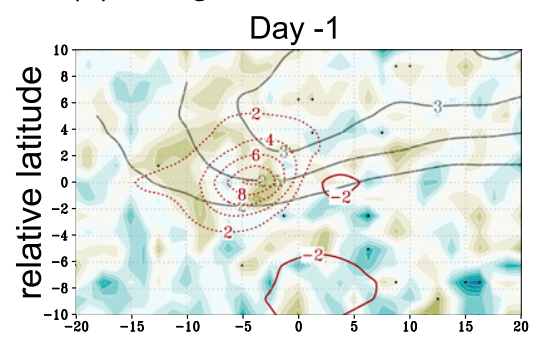

(b) Non-trough-related TDDs

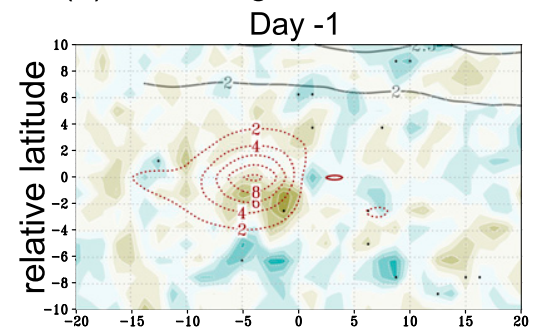

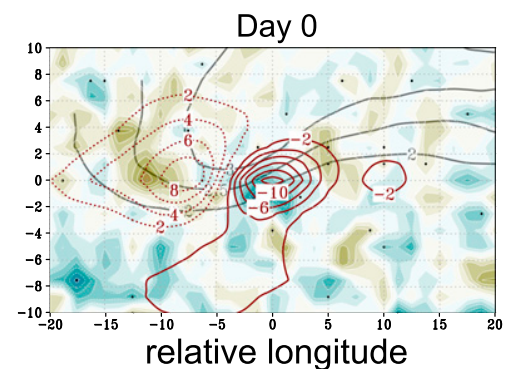

relative longitude

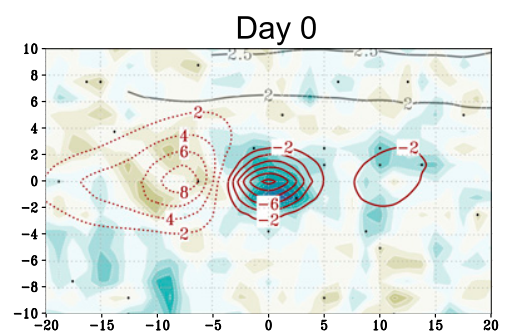

relative longitude
Divergence' @850hPa
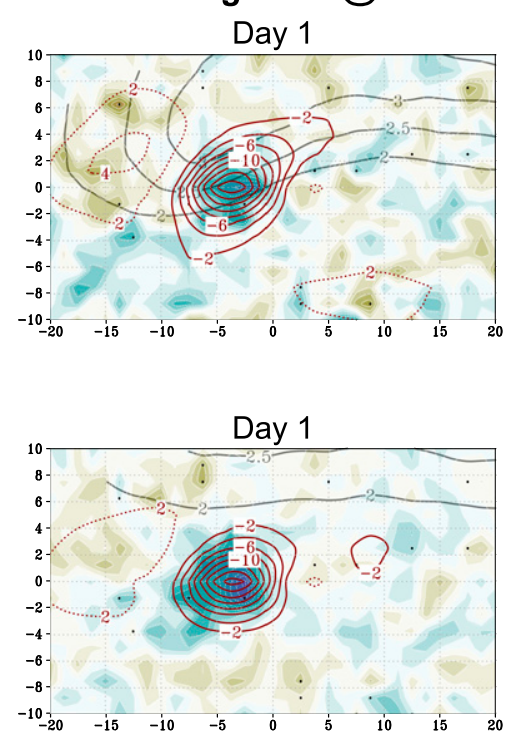

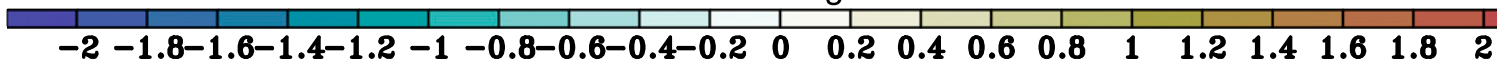

FIG. 8. As in Fig. 6, but the color shades indicate the composited horizontal divergence anomalies at 850 -hPa surface $\left(10^{-6} \mathrm{~s}^{-1}\right)$. The black dots denote where the values of the divergence show statistically significant differences at the $95 \%$ level. 
(a) Day -0.5 (TR) $\quad v^{\prime}, \zeta^{\prime}$

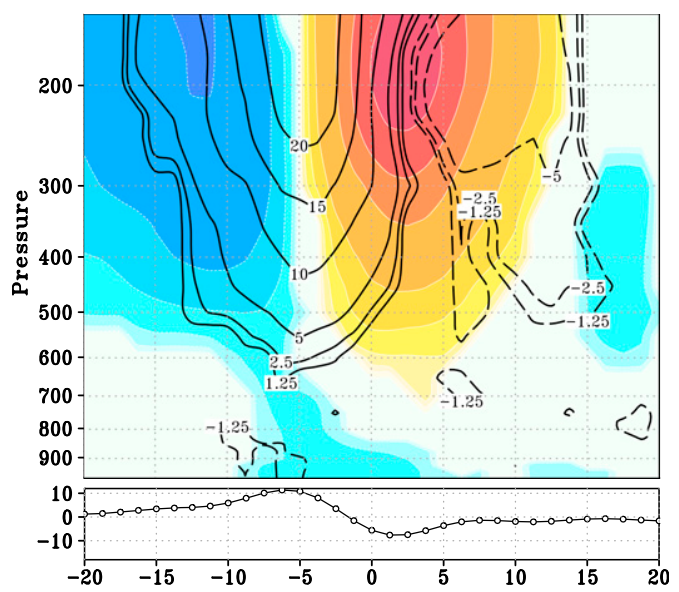

(b) Day 0 (TR)

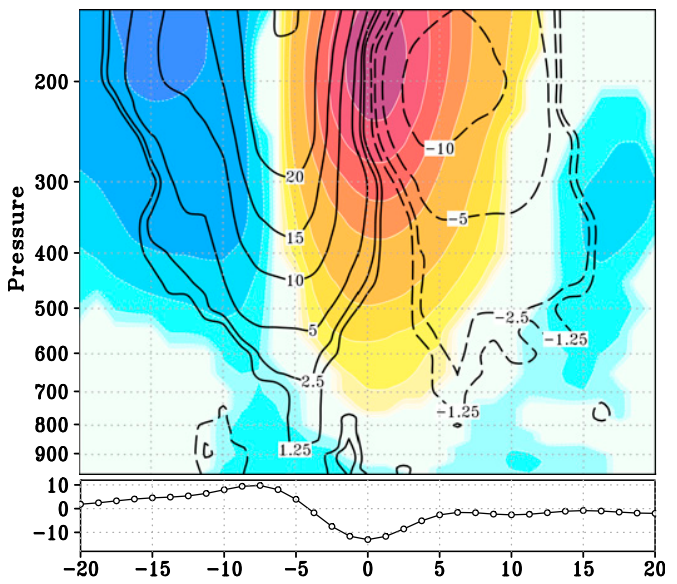

(c) Day +0.5 (TR)

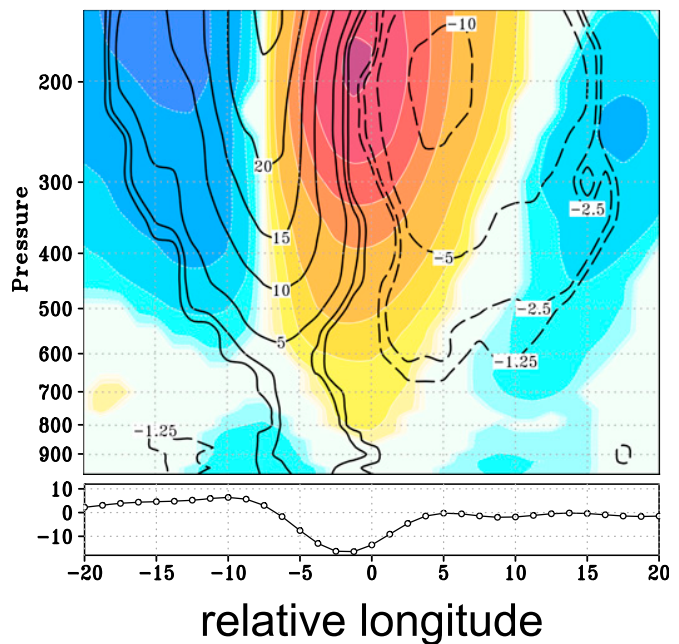

(d) Day -0.5 (NTR) $\quad v^{\prime}, \zeta^{\prime}$

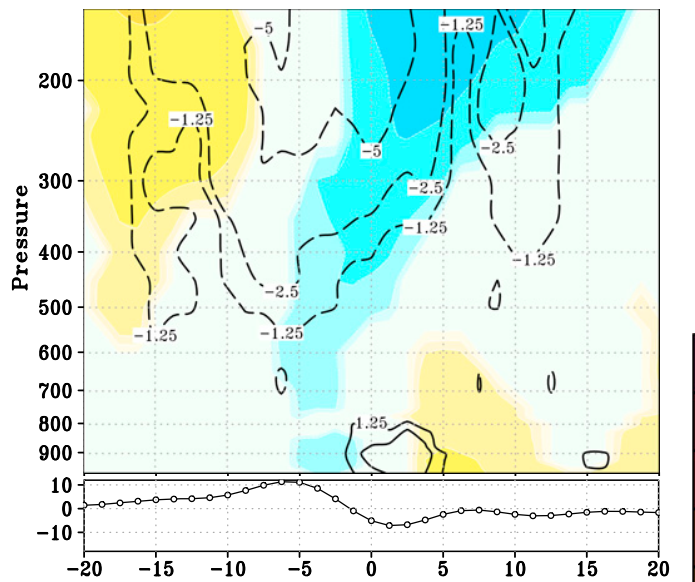

(e) Day 0 (NTR)

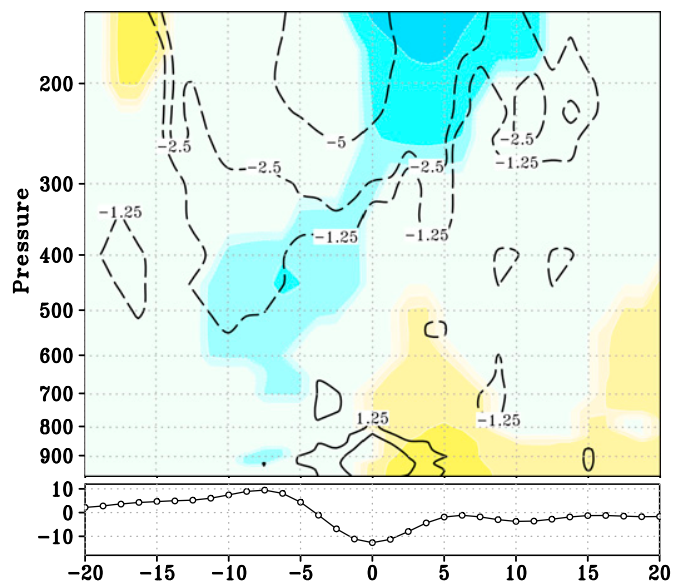

1.5

0.8

0.4

0.2

0.1

0

$-0.1$

$-0.2$

$-0.4$

$-0.8$

$-1.5$

(f) Day +0.5 (NTR)

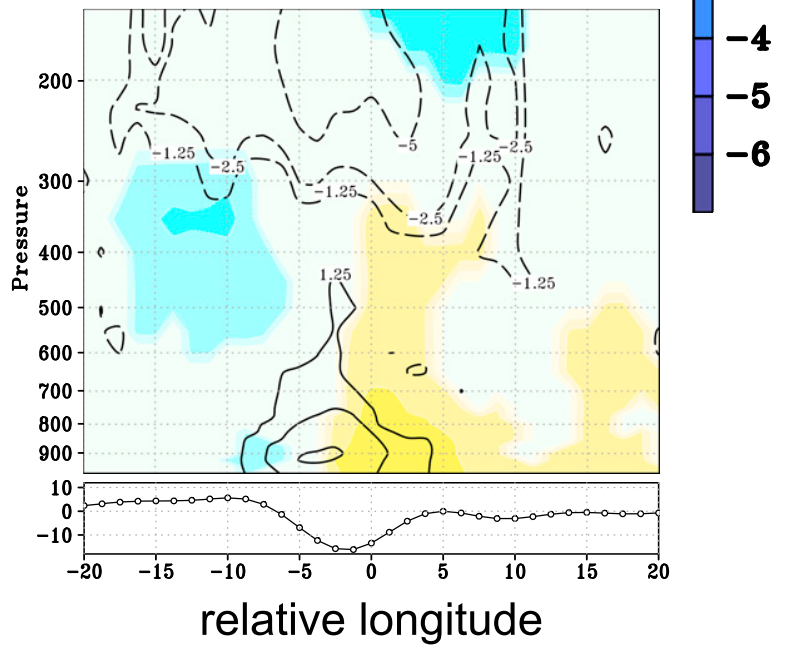

FIG. 9. (a)-(c) Zonal and vertical cross sections of composited anomalous relative vorticity $\zeta^{\prime}$ (black contours; $10^{-6} \mathrm{~s}^{-1}$ ) and meridional velocity $v^{\prime}$ (shades; $\mathrm{m} \mathrm{s}^{-1}$ ) at the latitude where the occurrences of TR-TDDs are observed. Rows correspond to (top to bottom) day $-0.5,0$, and +0.5 , respectively. Anomalies are defined as the differences from the 34 -yr summertime climatological mean at each grid. Solid (dashed) black contours denote the positive (negative) vorticity anomaly with the first contour starting from $(-) 1.25\left(10^{-6} \mathrm{~s}^{-1}\right)$. Zero contours are omitted. Note that only statistically significant values at the $95 \%$ level are plotted. The plot below each figure shows the value of filtered $T_{b}(\mathrm{~K})$, which depicts the position of the TDD. (d)-(f) As in (a)-(c), but composites are taken for the initiation events of NTR-TDDs. 
(a) Day -0.5 (TR) $\quad \theta^{\prime}, \omega^{\prime}$

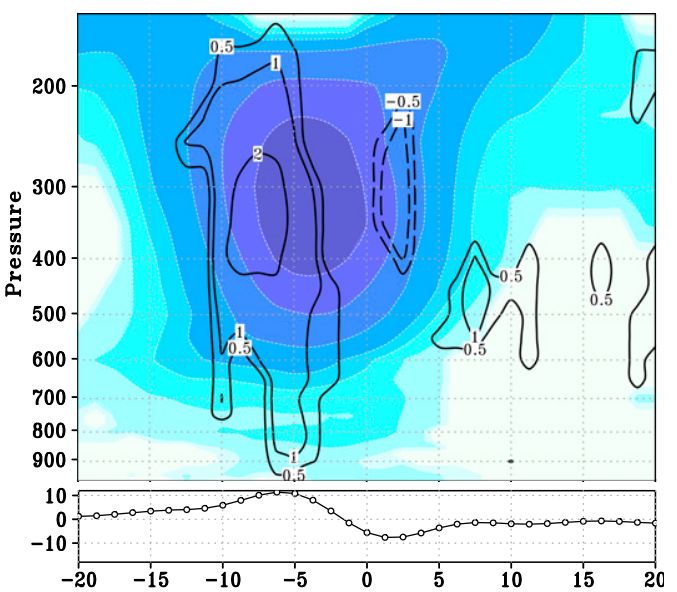

(b) Day 0 (TR)

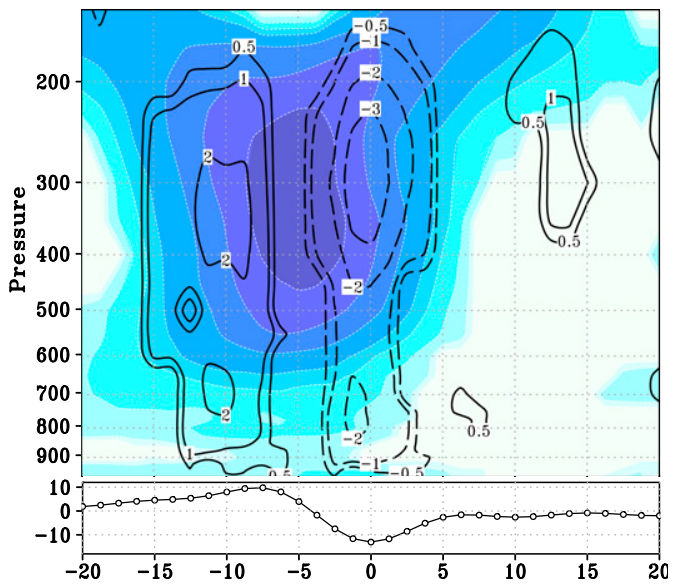

(c) Day +0.5 (TR)

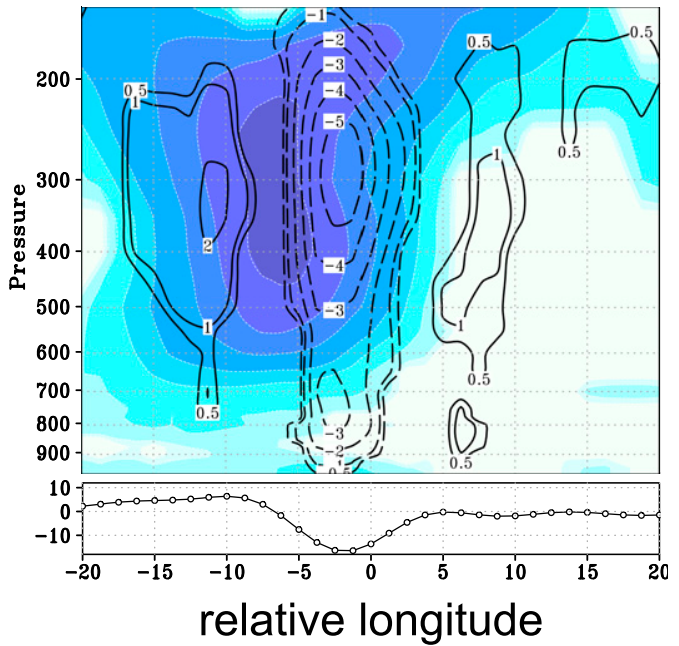

(d) Day -0.5 (NTR) $\quad \theta^{\prime}, \omega^{\prime}$

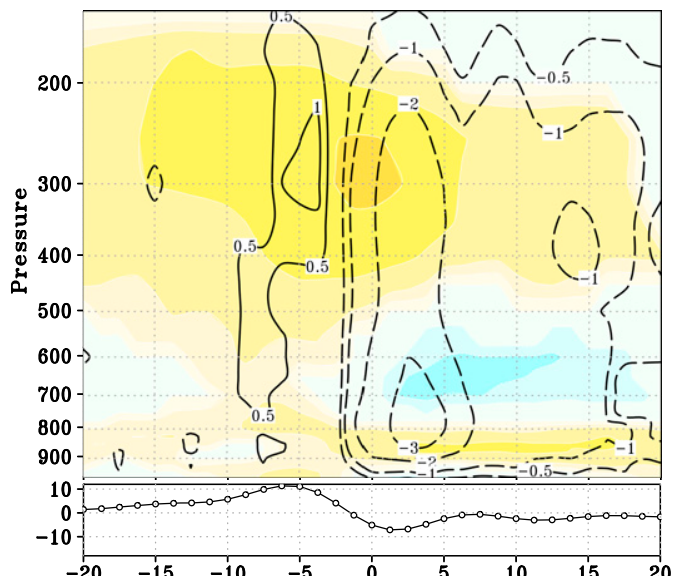

(e) Day 0 (NTR)

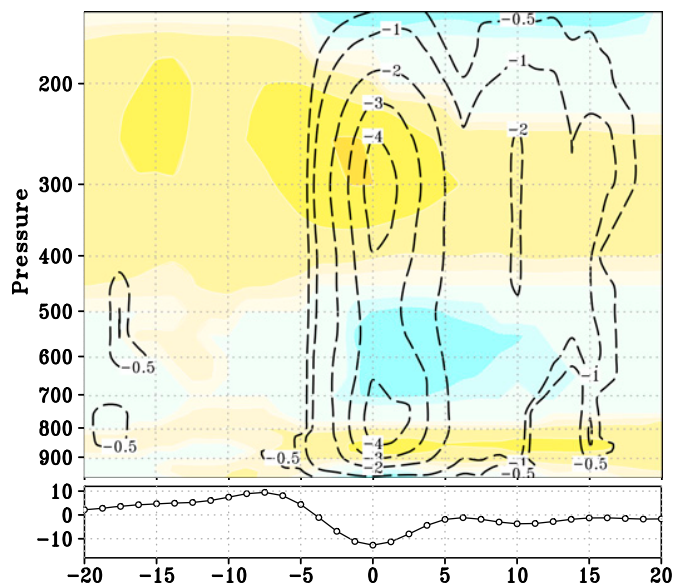

(f) Day +0.5 (NTR)

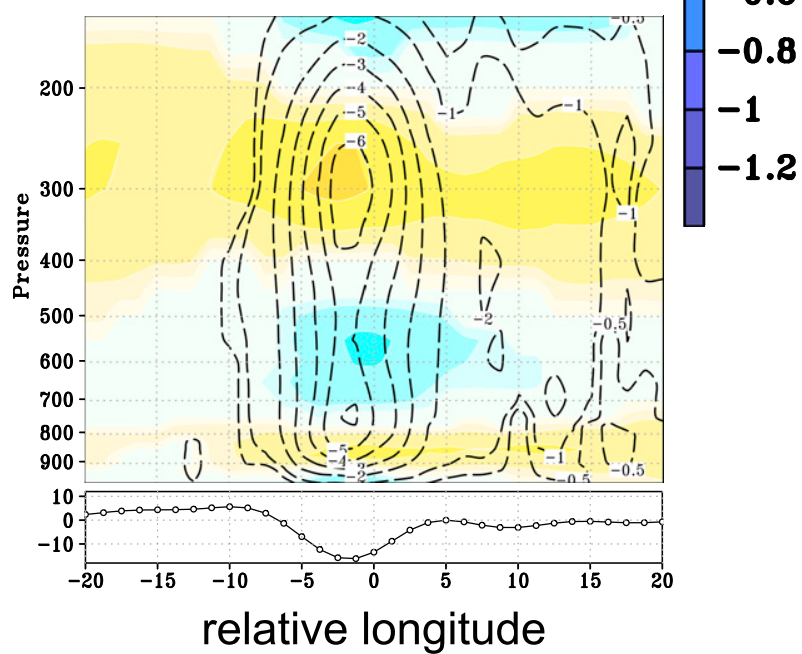

FIG. 10. (a)-(f) As in Fig. 9, but the contours and colors show the anomalous pressure velocity $\omega^{\prime}\left(10^{-2} \mathrm{~Pa} \mathrm{~s}^{-1}\right)$ and potential temperature $\theta^{\prime}(\mathrm{K})$, respectively. Dashed (solid) black contours denote the negative (positive) pressure velocity anomaly, which mean anomalous updraft (downdraft). 
(a) Day 0

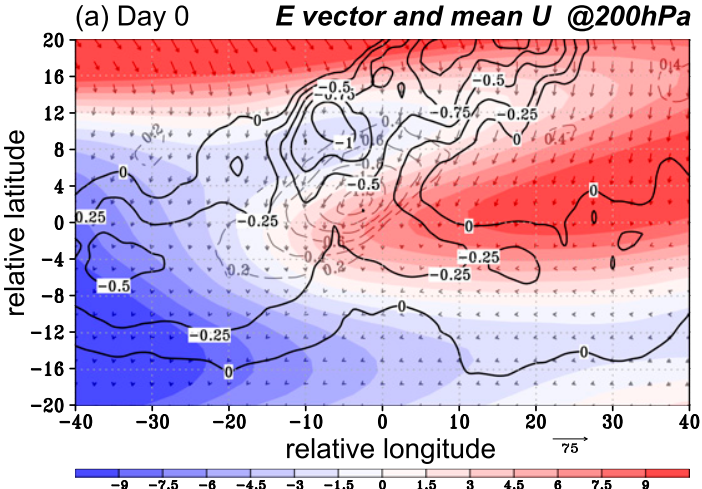

(b) Day 0

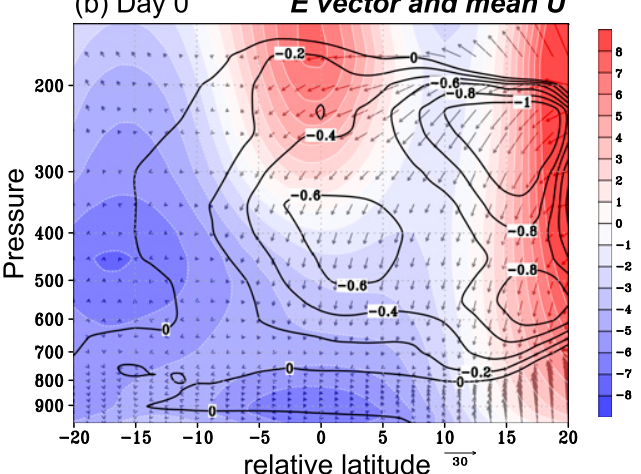

FIG. 11. (a) Day 0 composites of upper-level wave activity and mean zonal wind (on 200-hPa surface) associated with the occurrence of TR-TDDs. Black contours show the value of $\overline{v^{\prime} \theta^{\prime}}\left(\mathrm{m} \mathrm{s}^{-1} \mathrm{~K}\right)$, whose negative values indicate downward-traveling wave activity flux. The positive contours are omitted. Thin-dashed contours denote positive PV anomalies on the $360-\mathrm{K}$ surface, which mark the position of TUTT. The contour interval is $0.2 \mathrm{PVU}$ with first contour at 0.2 PVU. The color shades show the 10-day mean zonal wind $\bar{u}\left(\mathrm{~m} \mathrm{~s}^{-1}\right)$. Vectors represent the wave activity flux, given by $\mathbf{E}=\left[\left(\overline{v^{\prime 2}-u^{\prime 2}}\right) / 2,-\overline{u^{\prime} v^{\prime}}\right]\left(\mathrm{m}^{2} \mathrm{~s}^{-2}\right)$ (Trenberth 1986). (b) South-to-north vertical cross section of (a), averaged over relative longitude from $-5^{\circ}$ to $+5^{\circ}$. Contours and the color are as in (a). Vectors represent $\left[-\overline{u^{\prime} v^{\prime}} \propto E_{y}, 15 \times \overline{v^{\prime} \theta^{\prime}} \propto E_{z}\right]$. The scale of vertical component is adjusted to have better visual clarity.

10d-f). Alternatively, in the TR-TDD cases the negative pressure velocity first occurs to the east of the upper-level trough (Fig. 10a) and appears to become coupled with the lowerlevel rising motion as the disturbance deepens. We therefore hypothesize that the updraft in the upper troposphere in the TR-TDD cases is associated more with the dynamical effect of upper-level circulation than with the diabatic heating.

\section{d. The upper-level circulation and wave activity}

While NTR-TDDs originate in a moist environment with large-scale convergence in the lower troposphere (Figs. 4 and 5), TR-TDDs appear to originate in a different way. In a previous study, Tam and Li (2006) examined the three-dimensional wave activity flux associated with tropical synopticscale disturbances and showed that the southward and downward-propagating wave energy flux from the midlatitude converges in the tropical mid troposphere, especially near the date line. They hypothesized that the extratropical forcing around the region may act as a cause of tropical synoptic-scale disturbances. In this study, TR-TDDs are extracted as the TDDs associated with a high PV value around the tropopause (see section $2 b$ and Fig. 3b). Here, to check whether we investigate the same phenomenon (Tam and Li 2006), the threedimensional wave activity flux is calculated.

Figure 11 shows upper-level wave activity flux at day 0 of the composite. The E vector at $200 \mathrm{hPa}$, shown in Fig. 11a, is given by $\mathbf{E}=\left[\left(\overline{v^{\prime 2}-u^{\prime 2}}\right) / 2,-\overline{u^{\prime} v^{\prime}}\right]$ (Trenberth 1986), and the sign of $\overline{v^{\prime} \theta^{\prime}}$ indicates the vertical direction of the flux. Here we computed the time-mean variables (denoted by an overbar) using a filtering time of 10 days. From Fig. 11a, it is clear that the upper-level positive PV anomaly, which marks the position of the TUTT, is associated with the convergence of the upper-level wave activity flux along the waveguide, or the areas where $\bar{u}>0$, in which Rossby waves can propagate.
These wave activities arise in the northern latitudes, indicating a forcing from the extratropics to the tropics. Although their original source cannot be confirmed from this figure, midlatitude baroclinic waves are considered to be responsible for these phenomena (Tam and Li 2006). The southwardpropagating wave activity flux has negative values of $\overline{v^{\prime} \theta^{\prime}}$ around the initiation point, which indicates that the flux is downward-traveling. The south-to-north vertical cross section of $\overline{v^{\prime} \theta^{\prime}}$ in Fig. 11b further shows a southward-downward flux converging in the middle to lower troposphere. These statistical features of the upper-level wave activity associated with the initiation of TR-TDDs are consistent with Tam and Li's (2006) empirical orthogonal function analysis results (their Figs. 9 and 10). They note that "[o]ne possibility is that the summertime synoptic-scale disturbances might be related to PV intrusion into the Tropics or Rossby wave breaking." The results in this paper support their interpretation by explicitly dealing with the PV intrusion associated with TDD occurrences.

In the following section, we further clarify the role of upperlevel dynamical effects on the initiation of TR-TDDs by comparing dynamically and diabatically driven upwelling by deriving the respective QG $\omega$ equations for these phenomena.

\section{A comparison of the effects of the dynamical forcing associated with upper-level troughs and the diabatic heating associated with cumulus convection}

As shown in section 3, TR-TDDs occur under relatively dry and less convergent large-scale conditions, suggesting that there is a mechanism capable of modifying the environment that is somewhat favorable to initiating disturbances. Some hints to identify this mechanism can be derived from the plots of vertical motion and wave activity flux in Figs. 10 and 11, 
respectively. The upward vertical velocity observed in the mid- to upper troposphere to the east of the TUTT precedes the occurrence of TR-TDDs. Here we further reveal the contribution of upper-level circulation by performing a detailed diagnosis of the vertical motion described in section $2 \mathrm{c}$ and then compare the effects of the dynamical forcing and latentheat release associated with convection.
Figure 12 shows vertical cross sections of the composited dynamical forcing terms [the first and second terms on the right-hand side of Eq. (1)] and associated pressure velocities $\omega_{D}$ (Figs. 12a-e), the latent heating term [the third term on the right-hand side of Eq. (1)] and $\omega_{\text {LH }}$ (Figs. 12f-j), and relative humidity anomalies (Figs. $12 \mathrm{k}-\mathrm{o}$ ). The cross sections are taken from northwest to southeast with the centers corre- (a) Day -2

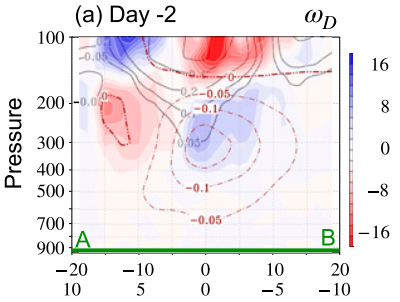

(b) Day -1.5

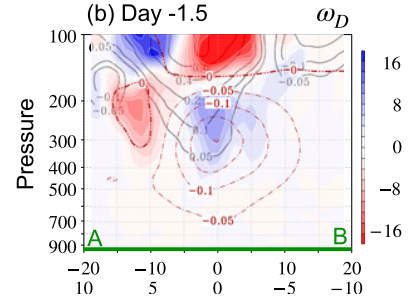

(c) Day -1

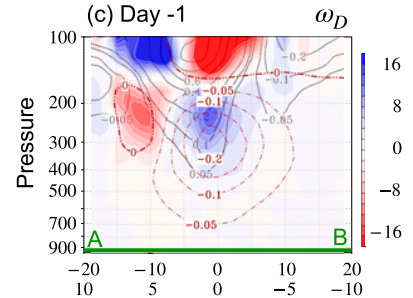

(d) Day -0.5

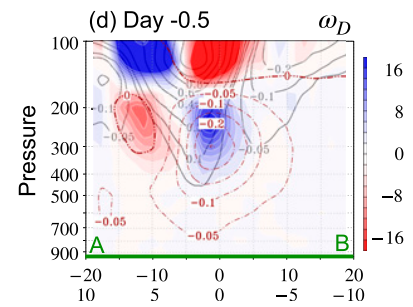

(e) Day 0

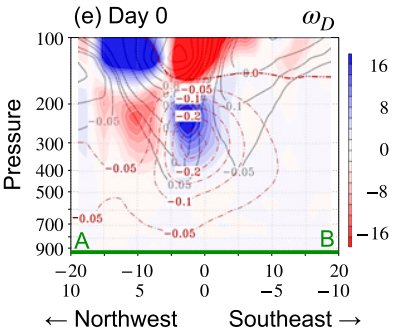

(f) Day -2

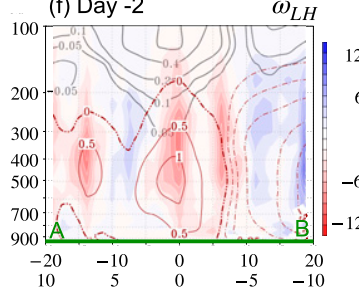

(g) Day -1.5

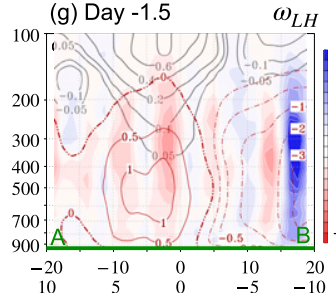

(h) Day -1

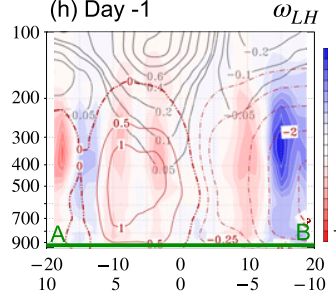

(i) Day $-0.5 \quad \omega_{L H}$

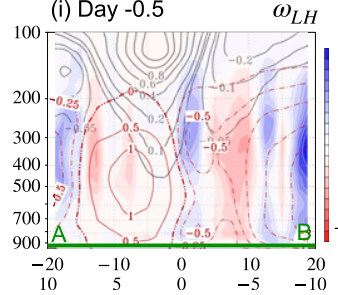

(j) Day 0

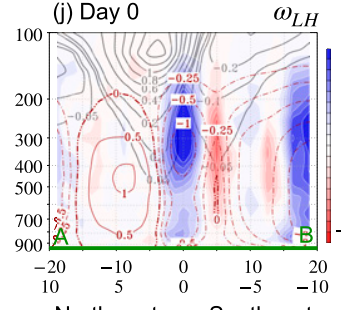

(k) Day -2

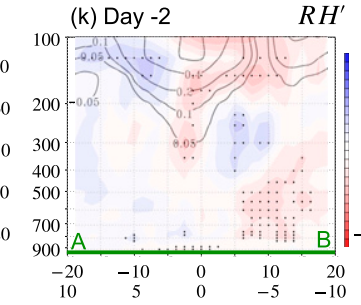

(l) Day -1.5 $R H^{\prime}$

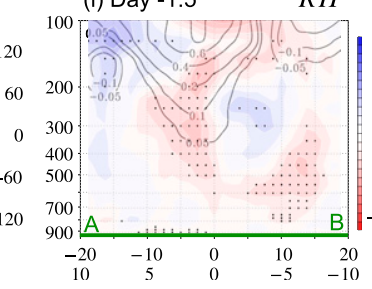

(m) Day -1

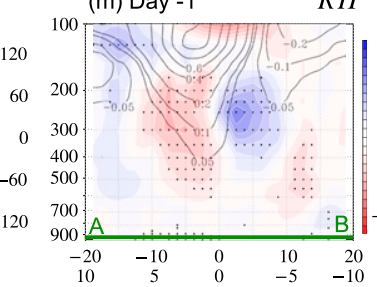

(n) Day -0.5

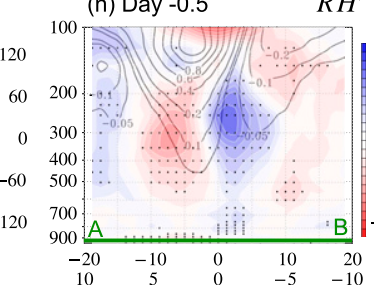

(o) Day $0 \begin{array}{clll}5 & & -5 & -10 \\ R H^{\prime}\end{array}$

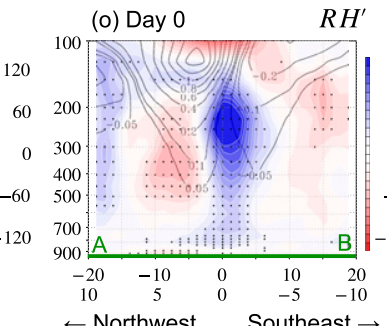

(p) Day -2 (NTR) $R H^{\prime}$

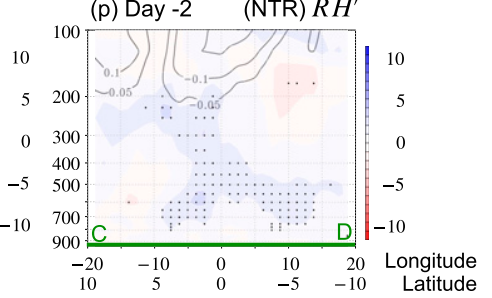

\begin{tabular}{ll} 
(q) Day -1.5 (NTR) $R H^{\prime}$ \\
\hline
\end{tabular}

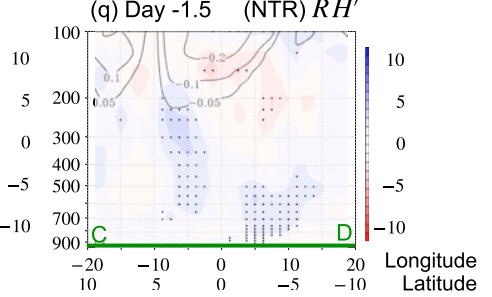

$\begin{array}{ll}\text { (r) Day }-1 \quad \text { (NTR) } R H^{\prime} & \end{array}$

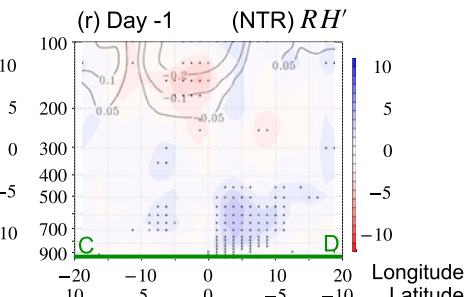

(s) Day -0.5 (NTR) $R H^{\prime}$
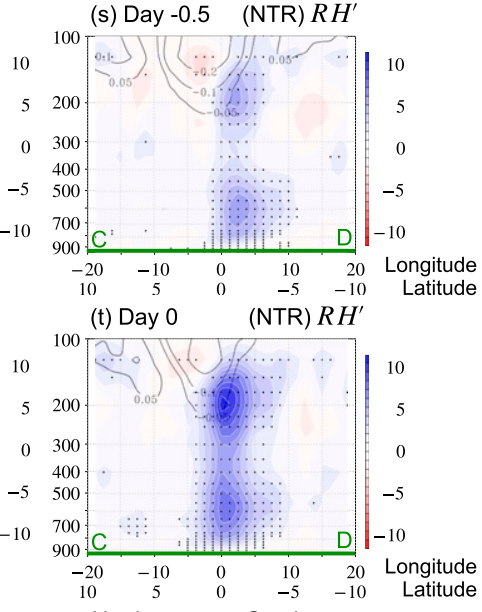

$\leftarrow$ Northwest $\quad$ Southeast $\rightarrow$

FIG. 12. Vertical cross sections of lead-lag composited variables on (a)-(o) TR-TDDs and (p)-(t) NTR-TDDs (top to bottom) from day -2 to day 0 . The cross section for (a)-(o) and (p)-(t) is from A to B and from C to D in Figs. 6a and 6b, respectively. Black contours show PV anomaly (PVU). The color shades indicate (a)-(e) the sum of the dynamical forcing $\left(10^{-20} \mathrm{~kg}^{-1} \mathrm{~m} \mathrm{~s}^{-1}\right)$ in the QG $\omega$ equation [Eq. (1) in the text], (f)-(j) the diabatic heating term $\left(10^{-20} \mathrm{~kg}^{-1} \mathrm{~m} \mathrm{~s}^{-1}\right)$, and $(\mathrm{k})-(\mathrm{t})$ relative humidity anomaly (\%). In (a)-(e), dynamically driven updraft $\left(\omega_{D}\right)$ is indicated by red contours of $0,-0.05,-0.1,-0.15,-0.2$, and $-0.25 \times 10^{-2} \mathrm{~Pa} \mathrm{~s}^{-1}$. In (f)-(j), latent-heating-driven updraft $\left(\omega_{\mathrm{LH}}\right)$ is indicated by red contours of $1,0.5,0,-0.25,-0.5,-1,-2$, and $-3 \times 10^{-2} \mathrm{~Pa} \mathrm{~s}^{-1}$. The black dots in $(\mathrm{k})-(\mathrm{t})$ denote where the value of relative humidity anomaly shows statistically significant difference from the climatological value at the $95 \%$ level. 
sponding to the initiation points of disturbance. These cross sections, nearly perpendicular to the axis of the upper-level trough (see Fig. 6a), enable us to obtain clearer differences between the northwest and southeast sides of the TUTT.

It is seen from Figs. 12a-e that the dynamical forcing has opposite signs between the northwest and the southeast sides of the TUTT. The forcing is primarily caused by the convergence of the $\mathrm{Q}$ vector, as the value of the $\beta$ effect term is usually one-fifth or less (not shown). Corresponding to the positive dynamical forcing, the dynamically induced upwelling $\omega_{D}$ has a peak at approximately $300 \mathrm{hPa}$ and extends to the midtroposphere. The dynamical ascent to the southeast of the upper-level trough precedes the initiation of lower-level disturbances and persists as the disturbance grows.

The latent-heat-driven ascent is shown in Figs. 12f-j. As seen in Figs. 6-8, the northwest side of the TUTT is a convectively inactive region (denoted by the positive filtered $T_{b}$ ), and therefore the latent heating in that region is mostly negative in Figs. $12 \mathrm{f}-\mathrm{j}$. The positive latent heating and updraft associated with convection are apparent at the initiation points on days -0.5 and 0 . Note that the intense heating and the induced strong upwelling in the southeast part of Figs. $12 \mathrm{~g}$ and $12 \mathrm{~h}$ are not necessarily relevant to the initiation of TRTDDs because there are no clear signals of negative filtered $T_{b}$ values, which propagate toward the northwest from the southeast (see Figs. 6-8). Thus, it is seen from Figs. $12 \mathrm{f}-\mathrm{j}$ that the deep convection that leads to the initiation of TR-TDDs and the associated latent-heat-driven updraft appear to occur after day -1 , which is consistent with the date on which the negative value of filtered $T_{b}$ is observed for the first time in Figs. 6-8.

It should be emphasized that moistening in the mid- to upper troposphere is observed at the southeast side of the TUTT, as shown in Figs. 12k-O. A positive relative humidity anomaly with a statistically significant intensity appears and grows in association with the approach of the high-PV anomaly in the upper troposphere, indicating that the sustained dynamical updraft $\left(\omega_{D}\right)$ at the southeast side of the trough plays an important role in the moistening. Note that the core of the $\omega_{D}$ does not line up with the positive relative humidity anomaly (e.g., $0^{\circ}, 0^{\circ}$ in Fig. $12 \mathrm{c}$ and $1.25^{\circ} \mathrm{S}, 2.5^{\circ} \mathrm{E}$ in Fig. $12 \mathrm{~m}$ ). This is because the west side of the TUTT corresponds to the convectively inactive area (Figs. 5-8) where the anomalous descent predominates (Figs. 10a-c and $12 \mathrm{f}-\mathrm{j}$ ) and dries out the atmosphere. Additionally, it is seen that the moistening in the mid- to upper troposphere by day -1 can be attributed to both the vertical advection of moist air by the sustained dynamical updraft and the horizontal advection, especially that produced by the anomalous southerly wind at the southeast side of the TUTT (see Fig. S3). Although the positive relative humidity anomaly is present only in the mid- to upper troposphere before day -1 , it couples with the lower-level humid air accompanying the previously mentioned deep convection at around day -0.5 and extends to the entire troposphere by the day 0 .

The overall structure of vertical motion described above closely matches the anomalous total pressure velocity (cf.
Figs. 12d,e,i,j with Figs. 10a,b). However, the actual value of total upward vertical velocity is larger than that diagnosed in this study (not shown), indicating that the climatological large-scale upwelling over entire tropical troposphere cannot be represented only by the QG $\omega$ equation. Despite the incompleteness of the QG-scaling analysis, however, it effectively explains the perturbations of both vertical motion and humidity that occur in association with the upper-level highPV intrusion, suggesting that the large-scale extratropical forcing plays a crucial role in the TR-TDD initiation process.

For a further comparison between the TR-TDDs and NTR-TDDs, Figs. 12p-t show the vertical profile of relative humidity anomaly for NTR-TDD-cases. We emphasize the statistically significant upper-level moist anomaly starting from day -2 in TR-TDD composite. On the other hand, the upper-level positive relative humidity anomalies in NTRTDDs is found only after day -0.5 . This is most likely the result of deep convection, which can be confirmed with the negative value of filtered $T_{b}$ (Fig. 10d). To initiate TR-TDDs without an anomalously moist lower troposphere, the moistening role of the upper-level trough may play an essential role.

\section{Discussion}

After the latent-heat release accompanied by deep convection occurs, as shown in Figs. $12 \mathrm{a}-\mathrm{e}$ and $12 \mathrm{f}-\mathrm{j}$, the total fluctuation of the vertical motion is dominated by latentheat-driven upwelling $\left(\omega_{\mathrm{LH}}\right)$. Yokoyama et al. (2020) studied the effects of an upper-tropospheric trough on a summertime heavy rainfall event in Japan, and Nie and Fan (2019) investigated the roles of dynamical forcing and diabatic heating on summertime extreme precipitation at the southern flank of the subtropical jet. Both studies pointed out the predominance of $\omega_{\mathrm{LH}}$ in the QG $\omega$ results to the south of the troughs. Although the dynamical effect was found to be smaller than the diabatic heating effect in the mature stage of TR-TDDs, the results of these studies suggest that its contribution to the overall vertical motion was not negligible, especially in conditioning the environment for convection to occur. This is consistent with our results shown in Figs. $12 \mathrm{a}-\mathrm{e}$ and $12 \mathrm{f}-\mathrm{j}$, in which the sustained dynamical ascent at the southeast side of the upper-level trough is equal to or greater than the latent-heat-driven ascent before the mature stage.

Concerning the moistening associated with the high-PV intrusion in the mid- to upper troposphere uncovered in our results, Waugh (2005) examined this issue. They analyzed upper-tropospheric humidity obtained using satellite-based measurements and found high relative humidity to the east of a PV intrusion into the northern subtropics. Whereas the air in that region had been moistened, the air within the intrusion was found to be desiccated by the transport of dry air from the stratosphere. These features are fully consistent with the relative humidity distribution shown in Figs. 12k-o.

The impact of mid- and upper-level humidity on tropical convection has been indicated by many previous studies as 
reviewed by Sherwood et al. (2010). Among them, Brown and Zhang (1997) found a strong correlation between moisture at mid- to upper levels and rainfall during Tropical Ocean Global Atmosphere Coupled Ocean-Atmosphere Response Experiment. Takemi et al. (2004), who conducted idealized cloud-resolving model sensitivity simulations, found that heights of tropical oceanic cumulus were more sensitive to the midlevel $(\sim 500 \mathrm{hPa})$ relative humidity than the static stability profile. Takayabu et al. (2006) supported the importance of midlevel humidity utilizing the upper-air rawinsonde observations over the western tropical Pacific Ocean and those over three Asian Monsoon Experiment stations of the Global Energy and Water Exchanges (GEWEX) project.

Another role that TUTTs possibly play in promoting the TR-TDD initiation would be the destabilization of the atmospheric stratification. As seen in Figs. 10a-c, TR-TDD initiation is accompanied by significant cold anomalies in the middle to upper troposphere. The cold air has its center on the axis of the upper-level trough, which is slightly $(\sim 500 \mathrm{~km})$ west of the initiation point of TR-TDDs. Considering the significant overlap of the cold anomalies aloft with the initiation location of TR-TDDs, the destabilization by the upper-level trough may facilitate the occurrence of TR-TDDs. Here, to briefly examine this issue, the convective available potential energy (CAPE) and the convective inhibition (CIN) are calculated and compared between TR-TDDs and NTR-TDDs, as indicators of the destabilization. The formulation of CAPE and CIN are as follows:

$$
\begin{gathered}
(\mathrm{CAPE})=\int_{z_{\mathrm{LFC}}}^{z_{\mathrm{LNB}}} g\left(\frac{T_{\text {parcel }}-T_{\mathrm{env}}}{T_{\mathrm{env}}}\right) d z \\
(\mathrm{CIN})=\int_{z_{\mathrm{start}}}^{z_{\mathrm{LFC}}} g\left(\frac{T_{\text {parcel }}-T_{\mathrm{env}}}{T_{\mathrm{env}}}\right) d z
\end{gathered}
$$

where LFC and LNB are the level of free convection and neutral buoyancy, respectively. To calculate this, the reference state was given by the temperature profile at the initiation point, and the starting level of the lifted parcel was set to $500 \mathrm{~m}$. Note that the results presented below do not differ qualitatively if a larger domain is used (not shown). After calculating CAPE and CIN for each TR-TDD initiation event, composites and their 95\% confidence intervals were gained. The results are shown in Figs. $13 \mathrm{a}$ and $13 \mathrm{~b}$. Similarly, Figs. $13 \mathrm{c}$ and $13 \mathrm{~d}$ show the values of CAPE and CIN with the virtual temperature correction (e.g., Doswell and Rasmussen 1994), in which the virtual temperature profile is used for the reference state. Figures $13 \mathrm{c}$ and $13 \mathrm{~d}$ show statistically significant separations in CAPE and CIN between TR- and NTR-TDDs. The highest CAPE in the TR-TDD cases is observed from day -2 to day 0 , which corresponds to the day (a)

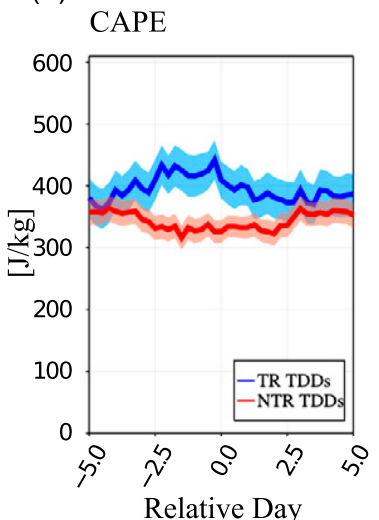

(e)

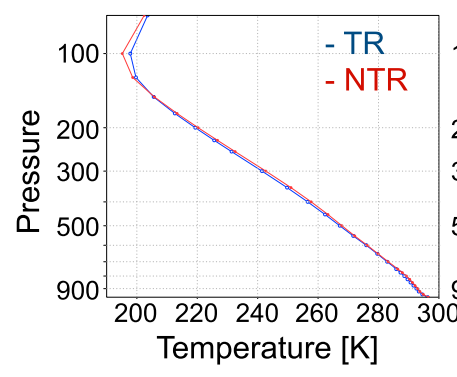

(b)

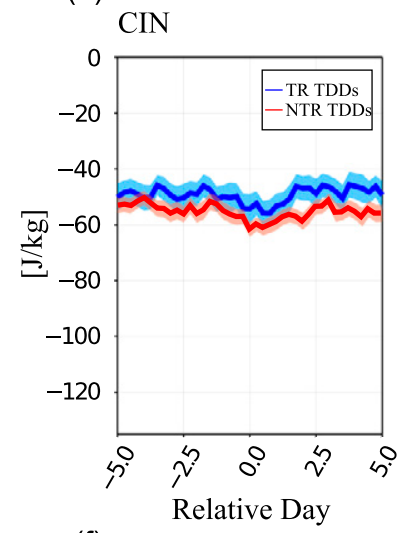

(f) (c)

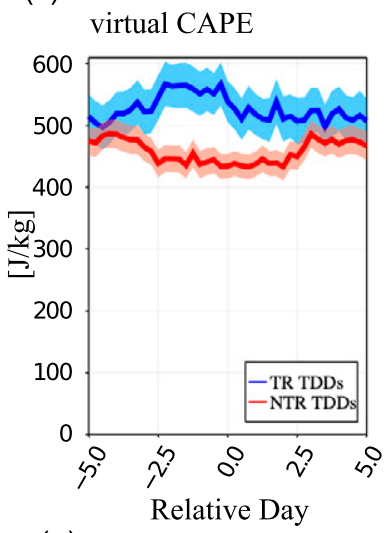

(g) (d)

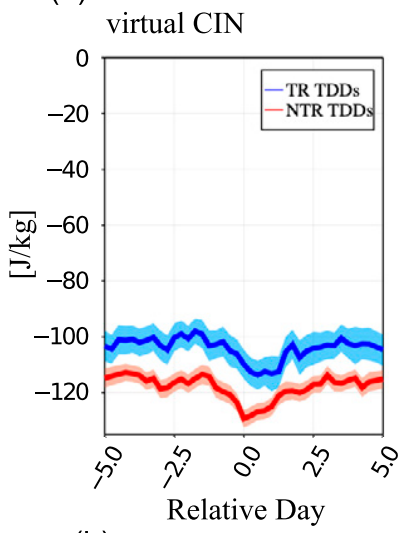

(h)

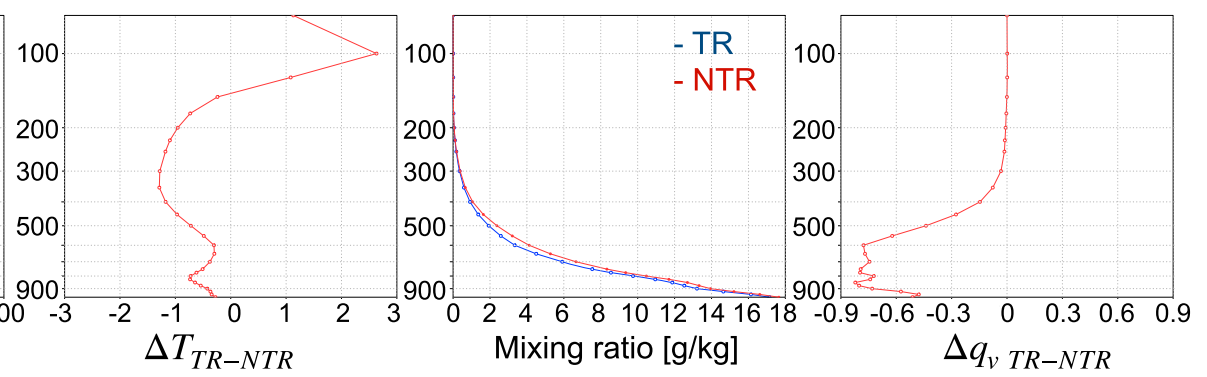

FIG. 13. (a)-(d) Composited CAPE and CIN without/with the virtual temperature correction. The blue and red lines represent the values for TR-TDDs and NTR-TDDs, respectively. The color shades indicate the $95 \%$ confidence intervals. (e), (g) Composited reference temperature and mixing ratio for TR- and NTR-TDDs and (f),(h) their differences. The reference state is given at the initiation point of each TRand NTR-TDD-initiation event. See the text in section 5 for details. 
of PV intrusion. The colder reference state in the mid and upper troposphere (Figs. 13e,f) in the TR-TDD cases seems to cause the higher value of CAPE. The general pattern shown in Figs. $13 \mathrm{c}$ and $13 \mathrm{~d}$ is almost identical to the nonvirtual one (Figs. 13a,b), except for the clear difference in CIN. This difference comes from the higher mixing ratio in the reference state in NTR-TDD cases, as shown in Figs. $13 \mathrm{~g}$ and $13 \mathrm{~h}$, which lowers parcel buoyancy and thus needs more energy to reach the LFC. In addition, the CAPE and CIN values in the TR-TDD cases are compared to those at the grid point coinciding with the center of the TUTT, where the largest upper-level cold anomaly is found. The result shows that the CAPE and CIN values at the TDD center from day -2.5 to day 0 are about $89 \%$ and $95 \%$, respectively, of the value at the center of the TUTT. Therefore, CAPE and CIN values are not significantly different at the $95 \%$ level, between the TDD center and the TUTT center. This suggests that the destabilizing effect of the upper-level trough extends to the area where the TR-TDD occurs.

After all, TUTTs can play a key role in promoting the initiation of TDDs via not only the moistening effect in the midto upper troposphere, but also the destabilizing effect of the upper-level trough. Note that the mid- to upper-level moistening at the southeast side of TUTTs shown in Figs. 12k-o is seen as only a few-percent change of relative humidity anomaly during the period, which is smaller than that in previous studies (e.g., Takemi et al. 2004). Further investigation may be necessary for a quantitative assessment of the relative importance of destabilization compared to the moistening in the mid- to upper troposphere.

\section{Summary and concluding remarks}

In this study, the statistical properties of trough-related tropical depression-type disturbances (TR-TDDs) and the contribution of the upper-level circulation associated with tropical upper-tropospheric troughs (TUTTs) to the initiation of TDDs are examined.

A wavenumber-frequency filtering method is used to extract TDD signals from the original brightness temperature field of the CLAUS-IR dataset to detect all TDD-event initiations over the tropical North Pacific during the 1984-2017 boreal summers. Each initiation event is classified as either trough-related (TR) or non-trough-related (NTR) based on whether the initiation point is located to the southeast of the TUTT. We then perform a lead-lag composite analysis of both TR-TDDs and NTR-TDDs to compare their differences in the environment as well as their structures. To better clarify the contribution of the upper-level circulation to the initiation of TDDs, we further examine the effects of dynamical forcing associated with TUTTs and diabatic heating associated with cumulus convection using the QG $\omega$ equation.

Figure 14 schematically summarizes the results obtained in this study.

- About $30 \%$ of TDD-initiation events in the region of $10^{\circ}-20^{\circ} \mathrm{N}$ are associated with the upper-level troughs (Fig. 4 and Table 1).
- TR-TDDs tend to occur under a drier environment with a less convergent ambient flow in the lower troposphere compared to NTR-TDDs (Fig. 5), which is a relatively unfavorable low-level condition for TDD initiation.

- The upper-level circulation associated with a PV intrusion, characterized by the sustained dynamical ascent, moistens the mid- to upper troposphere at the southeast side of the TUTT (Fig. 12). It is hypothesized that the relatively moist air in the mid- to upper troposphere can provide a favorable environment to maintain deep organized convection (e.g., Brown and Zhang 1997; Takemi et al. 2004; Takayabu et al. 2006).

- A higher CAPE value with a statistical significance is observed for TR-TDDs compared to NTR-TDDs (Fig. 13), suggesting that the effect of destabilization due to the cold air of the upper-level trough (Figs. 10a-c) also promotes the TR-TDD initiation.

- In contrast to TR-TDDs, NTR-TDDs tend to originate in a moist environment with large-scale convergence in the lower troposphere (Fig. 5). Their initiations may be explained by the wave energy accumulation (e.g., Kuo et al. 2001) or the instability of the mean flow (e.g., Ferreira and Schubert 1997) in the lower troposphere.

Though the initiation processes of NTR-TDDs are less focused in this study, it seems to be consistent with previous studies (see section 3b). In contrast, statistical features of TRTDDs listed above are revealed for the first time in this study, using the 34-yr record of observation-based data.

Note that, in total, the proportion of TR-TDDs in our analysis is still small compared to that of NTR disturbances (see Table 1), which means that most of TDDs occur without the influence of upper-level troughs. Although TR-TDDs are less common, our results with respect to TR-TDD formation and dynamics may shed some light on related topics. While Zhang et al. (2016) pointed that the frequent breaking of midlatitude Rossby waves suppressed Atlantic TC activity in August 2013, McTaggart-Cowan et al. (2013) found that the "trough induced" pathway is the most efficient pathway (except for the "nonbaroclinic" pathway) for tropical cyclogenesis in the western North Pacific. Fudeyasu and Yoshida (2019) reported that TCs influenced by upper-level cold lows in their genesis tend to remain at weak intensity but frequently make landfall in Japan. Though the development process of TR-TDDs is not a focus in this study, Galarneau et al. (2015) examined the difference between developing and nondeveloping TCs near upper-level PV streamers in the North Atlantic and found that the structure and intensity of the synoptic-scale anticyclone north of the incipient vortex plays a primary role. It remains to be unraveled whether this is true in the western North Pacific. These studies also suggest the importance of studying the relationship between the upper-level circulation and tropical convection.

Concerning time variability, Nath et al. (2017) revealed that the frequency of PV intrusions over Pacific Ocean has strong interannual variability as a result of El Niño-Southern Oscillation, with more events occurring under the La Niña condition as a result of the stronger equatorial westerly ducts. It can therefore be inferred that the occurrence frequency of 


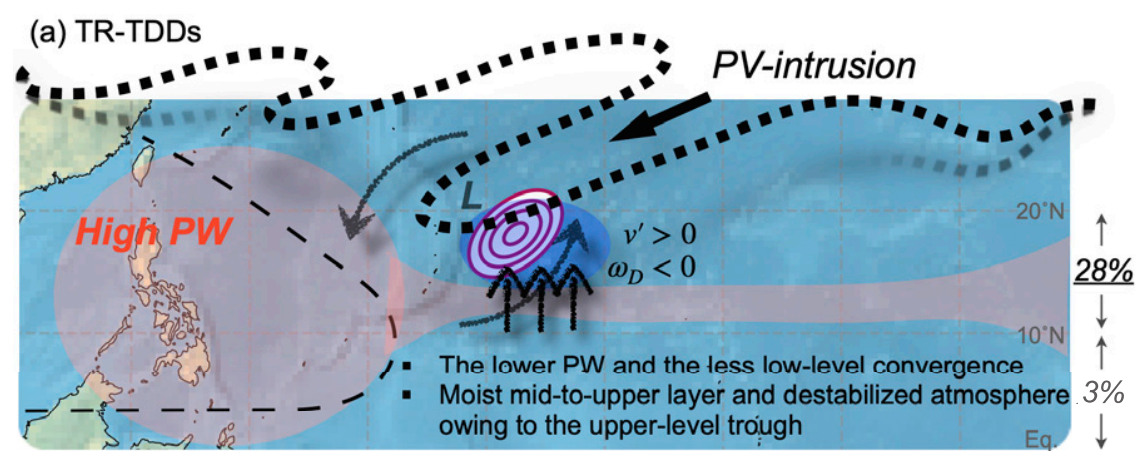

(b) NTR-TDDs

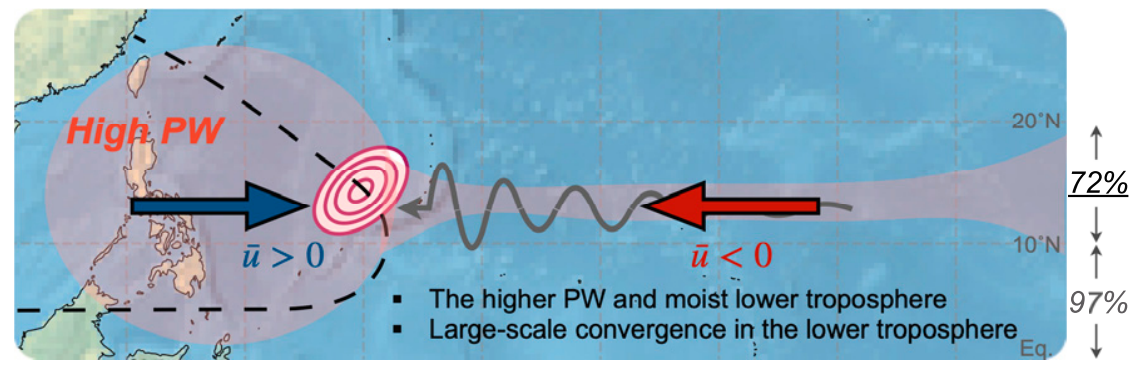

FIG. 14. Schematic summary of initiation processes of (a) TR-TDDs and (b) NTR-TDDs. (a) As in Fig. 3, the thick short-dashed black curve denotes the dynamically defined tropopause. The letter "L" represents the position of the upper-level trough associated with the PV-intrusion. The trough-related TDD illustrated by the purple envelope occurs at the southeast side of the upper-level trough. The shaded objects indicate objects in the mid- to upper troposphere. The present study reveals that the occurrence area indicated by the blue ellipse has the bulleted features (see texts for details). (b) As in (a), but the occurrence of NTR-TDDs is characterized by the region of high precipitable water (red shaded) and large-scale convergence in the lower troposphere (shown by blue and red arrows). The thin long-dashed black curve denotes the monsoon trough. The incoming initial perturbation shown by the gray arrow tends to be amplified via the wave energy accumulation at that region or the instability of mean flow (see text in section $3 b)$. The percentages on the right side of these panels are the same as those listed for 2.0 PVU in Table 1.

TR-TDDs under La Niña-like conditions might be greater than under El Niño-like conditions. Similarly, the dependency of TR-TDD initiation on intraseasonal variability and future changes in the atmosphere might be inferred in terms of the modulation of the Walker circulation. Finally, under a future warming climate the "bottom up" effect of atmospheric moisture content may further promote the initiation of organized deep convection (Bretherton et al. 2004), which might in turn result in the enhanced production of TR-TDDs for the same dynamical forcing.

Acknowledgments. The authors would like to express their gratitude to Dr. K. Kikuchi at the University of Hawaii for providing the merged CLAUS-IR dataset. We also thank Dr. C. Yokoyama for her help in obtaining JRA-55 and SSM/I data. The comments by the editor and three anonymous reviewers are greatly appreciated for improving the original manuscript. This research was performed by the Environment Research and Technology Development Fund (JPMEERF20192004) of the Environmental Restoration and Conservation Agency of Japan. This study was also supported by the University of Tokyo through a project "Research hub for the big data analysis of global water cycle and precipitation in changing climate." The first author acknowledges the financial support of IGPEES, WINGS Program, the University of Tokyo.

Data availability statement. The merged CLAUS-IR products analyzed in this study are a processed version of existing data and are openly available at https:/catalogue.ceda.ac.uk/ uuid/c2112bdd5f0ad698e70be6ab54c9a2ac (CLAUS) and at http://www.cpc.ncep.noaa.gov/products/global_precip/html/ wpage.full_res.shtml (Globally Merged IR). Further documentation about data processing is available in Dias et al. (2017). The Japanese 55-yr Reanalysis (JRA-55) data used during this study are openly available at https://doi.org/10. 5065/D6HH6H4, which is from the Research Data Archive at the National Center for Atmospheric Research, Computational and Information Systems Laboratory as cited in Kobayashi et al. (2015). The SSM/I data are produced by Remote Sensing Systems. Data are available at www.remss. com/missions/ssmi. 


\section{REFERENCES}

Aiyyer, A. R., and J. Molinari, 2003: Evolution of mixed Rossbygravity waves in idealized MJO environments. J. Atmos. Sci., 60, 2837-2855, https://doi.org/10.1175/1520-0469(2003)060 $<2837$ :EOMRWI $>2.0$. CO;2.

Andrews, D. G., J. R. Holton, and C. B. Leovy, 1987: Middle Atmosphere Dynamics. Academic Press, 489 pp.

Bretherton, C. S., M. E. Peters, and L. E. Back, 2004: Relationships between water vapor path and precipitation over the tropical oceans. J. Climate, 17, 1517-1528, https://doi.org/10. 1175/1520-0442(2004)017<1517:RBWVPA > 2.0.CO;2.

Briegel, L. M., and W. M. Frank, 1997: Large-scale influences on tropical cyclogenesis in the western North Pacific. Mon. Wea. Rev., 125, 1397-1413, https://doi.org/10.1175/1520-0493 (1997) $125<1397:$ LSIOTC>2.0.CO;2.

Brown, R. G., and C. Zhang, 1997: Variability of midtropospheric moisture and its effect on cloud-top height distribution during TOGA COARE. J. Atmos. Sci., 54, 2760-2774, https://doi. org/10.1175/1520-0469(1997)054<2760:VOMMAI>2.0.CO;2.

Chang, C.-P., V. F. Morris, and J. M. Wallace, 1970: A statistical study of easterly waves in the western Pacific: July-December 1964. J. Atmos. Sci., 27, 195-201, https://doi.org/10.1175/15200469(1970)027<0195:ASSOEW>2.0.CO;2.

Chang, M., C. Ho, J. C. L. Chan, M. Park, S. Son, and J. Kim, 2019: The tropical transition in the western North Pacific: The case of Tropical Cyclone Peipah (2007). J. Geophys. Res. Atmos., 124, 5151-5165, https://doi.org/10.1029/2018JD029446.

Chen, G., and C. Y. Tam, 2012: A new perspective on the excitation of low-tropospheric mixed Rossby-gravity waves in association with energy dispersion. J. Atmos. Sci., 69, 1397-1403, https://doi.org/10.1175/JAS-D-11-0331.1.

Dias, J., N. Sakaeda, G. N. Kiladis, and K. Kikuchi, 2017: Influences of the MJO on the space-time organization of tropical convection. J. Geophys. Res. Atmos., 122, 8012-8032, https:// doi.org/10.1002/2017JD026526.

Dickinson, M., and J. Molinari, 2002: Mixed Rossby-gravity waves and western Pacific tropical cyclogenesis. Part I: Synoptic evolution. J. Atmos. Sci., 59, 2183-2196, https://doi.org/10. 1175/1520-0469(2002)059<2183:MRGWAW>2.0.CO;2.

Doswell, C. A., and E. N. Rasmussen, 1994: The effect of neglecting the virtual temperature correction on CAPE calculations. Wea. Forecasting, 9, 625-629, https://doi.org/10.1175/15200434(1994)009<0625:TEONTV>2.0.CO;2.

Feng, T., X. Q. Yang, W. Zhou, R. Huang, L. Wu, and D. Yang, 2016: Synoptic-scale waves in sheared background flow over the western North Pacific. J. Atmos. Sci., 73, 4583-4603, https://doi.org/10.1175/JAS-D-16-0064.1.

Ferreira, R. N., and W. H. Schubert, 1997: Barotropic aspects of ITCZ breakdown. J. Atmos. Sci., 54, 261-285, https://doi.org/ 10.1175/1520-0469(1997)054<0261:BAOIB > 2.0.CO;2.

Fischer, M. S., B. H. Tang, and K. L. Corbosiero, 2017: Assessing the influence of upper-tropospheric troughs on tropical cyclone intensification rates after genesis. Mon. Wea. Rev., 145, 1295-1313, https://doi.org/10.1175/MWR-D-16-0275.1.

Fudeyasu, H., and R. Yoshida, 2019: Statistical analysis of the relationship between upper tropospheric cold lows and tropical cyclone genesis over the western North Pacific. J. Meteor. Soc. Japan, 97, 439-451, https://doi.org/10.2151/jmsj.2019-025.

Galarneau, T. J., R. McTaggart-Cowan, L. F. Bosart, and C. A. Davis, 2015: Development of North Atlantic tropical disturbances near upper-level potential vorticity streamers.
J. Atmos. Sci., 72, 572-597, https://doi.org/10.1175/JAS-D14-0106.1.

Heta, Y., 1991: The origin of tropical disturbances in the equatorial pacific. J. Meteor. Soc. Japan, 69, 337-351, https://doi.org/ 10.2151/jmsj1965.69.3_337.

Hodges, K. I., D. W. Chappell, G. J. Robinson, and G. Yang, 2000: An improved algorithm for generating global window brightness temperatures from multiple satellite infrared imagery. J. Atmos. Oceanic Technol., 17, 1296-1312, https://doi. org/10.1175/1520-0426(2000)017<1296:AIAFGG>2.0.CO;2.

Holland, G. J., 1995: Scale interaction in the western Pacific monsoon. Meteor. Atmos. Phys., 56, 57-79, https://doi.org/10.1007/ BF01022521.

Holton, J. R., 2004: An Introduction to Dynamic Meteorology. 4th ed. Elsevier Academic Press, 535 pp.

— , P. H. Haynes, M. E. McIntyre, A. R. Douglass, R. B. Rood, and L. Pfister, 1995: Stratosphere-troposphere exchange. Rev. Geophys., 33, 403-439, https://doi.org/10.1029/95RG02097.

Horinouchi, T., and A. Hayashi, 2017: Meandering subtropical jet and precipitation over summertime East Asia and the Northwestern Pacific. J. Atmos. Sci., 74, 1233-1247, https://doi.org/ 10.1175/JAS-D-16-0252.1.

Hoskins, B. J., M. E. McIntyre, and A. W. Robertson, 1985: On the use and significance of isentropic potential vorticity maps. Quart. J. Roy. Meteor. Soc., 111, 877-946, https://doi.org/10. 1002/qj.49711147002.

Janowiak, J. E., R. J. Joyce, and Y. Yarosh, 2001: A real-time global half-hourly pixel-resolution infrared dataset and its applications. Bull. Amer. Meteor. Soc., 82, 205-217, https://doi. org/10.1175/1520-0477(2001)082<0205:ARTGHH>2.3.CO;2.

Kelly, W. E., and D. R. Mock, 1982: A diagnostic study of upper tropospheric cold lows over the western North Pacific. Mon. Wea. Rev., 110, 471-480, https://doi.org/10.1175/15200493(1982)110<0471:ADSOUT>2.0.CO;2.

Kiladis, G. N., M. C. Wheeler, P. T. Haertel, K. H. Straub, and P. E. Roundy, 2009: Convectively coupled equatorial waves. Rev. Geophys., 47, RG2003, https://doi.org/10.1029/2008RG0 00266.

Kobayashi, S., and Coauthors, 2015: The JRA-55 reanalysis: General specifications and basic characteristics. J. Meteor. Soc. Japan, 93, 5-48, https://doi.org/10.2151/jmsj.2015-001.

Kuo, H. C., J. H. Chen, R. T. Williams, and C. P. Chang, 2001: Rossby waves in zonally opposing mean flow: Behavior in northwest Pacific summer monsoon. J. Atmos. Sci., 58, 1035-1050, https://doi.org/10.1175/1520-0469(2001)058<1035: RWIZOM $>2.0 . \mathrm{CO} ; 2$.

Lau, K.-H., and N.-C. Lau, 1990: Observed structure and propagation characteristics of tropical summertime synoptic scale disturbances. Mon. Wea. Rev., 118, 1888-1913, https://doi.org/10. 1175/1520-0493(1990)118<1888:OSAPCO > 2.0.CO;2.

$\longrightarrow$, and — 1992: The energetics and propagation dynamics of tropical summertime synoptic-scale disturbances. Mon. Wea. Rev., 120, 2523-2539, https://doi.org/10.1175/15200493(1992) $120<2523$ :TEAPDO $>2.0$. CO;2.

Li, T., 2006: Origin of the summertime synoptic-scale wave train in the western North Pacific. J. Atmos. Sci., 63, 1093-1102, https://doi.org/10.1175/JAS3676.1.

— B. Fu, X. Ge, B. Wang, and M. Peng, 2003: Satellite data analysis and numerical simulation of tropical cyclone formation. Geophys. Res. Lett., 30, 2122, https://doi.org/10.1029/ 2003 GL018556.

Liniger, M. A., and H. C. Davies, 2004: Seasonal differences in extratropical potential vorticity variability at tropopause 
levels. J. Geophys. Res., 109, D17102, https://doi.org/10.1029/ 2004JD004639.

Maloney, E. D., and M. J. Dickinson, 2003: The intraseasonal oscillation and the energetics of summertime tropical western North Pacific synoptic-scale disturbances. J. Atmos. Sci., 60, 2153-2168, https://doi.org/10.1175/1520-0469(2003)060<2153: TIOATE $>2.0 . \mathrm{CO} ; 2$.

McTaggart-Cowan, R., G. D. Deane, L. F. Bosart, C. A. Davis, and T. J. Galarneau, 2008: Climatology of tropical cyclogenesis in the North Atlantic (1948-2004). Mon. Wea. Rev., 136, 1284-1304, https://doi.org/10.1175/2007MWR2245.1.

—, T. J. Galarneau, — , R. W. Moore, and O. Martius, 2013: A global climatology of baroclinically influenced tropical cyclogenesis. Mon. Wea. Rev., 141, 1963-1989, https://doi.org/ 10.1175/MWR-D-12-00186.1.

Nath, D., W. Chen, H. F. Graf, X. Lan, and H. Gong, 2017: Contrasting subtropical PV intrusion frequency and their impact on tropospheric ozone distribution over Pacific Ocean in ElNiño and La-Niña conditions. Sci. Rep., 7, 11987, https://doi. org/10.1038/s41598-017-12278-7.

Nie, J., and B. Fan, 2019: Roles of dynamic forcings and diabatic heating in summer extreme precipitation in East China and the southeastern United States. J. Climate, 32, 5815-5831, https://doi.org/10.1175/JCLI-D-19-0188.1.

Nitta, T., and M. Yanai, 1969: A note on the barotropic instability of the tropical easterly current. J. Meteor. Soc. Japan, 47, 127-131, https://doi.org/10.2151/jmsj1965.47.2_127.

Postel, G. A., and M. H. Hitchman, 1999: A climatology of Rossby Wave breaking along the subtropical tropopause. $J$. Atmos. Sci., 56, 359-373, https://doi.org/10.1175/15200469(1999)056<0359:ACORWB > 2.0.CO;2.

Ramage, C. S., 1959: Hurricane development. J. Meteor., 16, $227-$ 237, https://doi.org/10.1175/1520-0469(1959)016<0227:HD >2. $0 . \mathrm{CO} ; 2$.

Riehl, H., 1948: On the formation of typhoons. J. Meteor., 5, 247265, https://doi.org/10.1175/1520-0469(1948)005<0247:OTFOT> 2.0.CO;2.

Ritchie, E. A., and G. J. Holland, 1999: Large-scale patterns associated with tropical cyclogenesis in the western Pacific. Mon. Wea. Rev., 127, 2027-2043, https://doi.org/10.1175/15200493(1999)127<2027:LSPAWT>2.0.CO;2.

Sadler, J. C., 1976: A role of the tropical upper tropospheric trough in early season typhoon development. Mon. Wea. Rev., 104, 1266-1278, https://doi.org/10.1175/1520-0493 (1976)104<1266:AROTTU>2.0.CO;2.

— 1978: Mid-season typhoon development and intensity changes and the tropical upper tropospheric trough. Mon. Wea. Rev., 106, 1137-1152, https://doi.org/10.1175/1520-0493 (1978)106<1137:MSTDAI >2.0.CO;2.

Sherwood, S. C., R. Roca, T. M. Weckwerth, and N. G. Andronova, 2010: Tropospheric water vapor, convection, and climate. Rev. Geophys., 48, RG2001, https://doi.org/10.1029/ 2009RG000301.
Shimamura, M., 1982: An application of GMS satellite data in the analysis of the upper cold low in the western North Pacific. Geophys. Mag., 40, 113-152.

Sobel, A. H., and C. S. Bretherton, 1999: Development of synoptic-scale disturbances over the summertime tropical Northwest Pacific. J. Atmos. Sci., 56, 3106-3127, https://doi.org/10. 1175/1520-0469(1999)056<3106:DOSSDO>2.0.CO;2.

Tai, K.-S., and Y. Ogura, 1987: An observational study of easterly waves over the eastern Pacific in the northern summer using FGGE data. J. Atmos. Sci., 44, 339-361, https://doi.org/10. 1175/1520-0469(1987)044<0339:AOSOEW >2.0.CO;2.

Takayabu, Y. N., and T. Nitta, 1993: 3-5 day-period disturbances coupled with convection over the tropical Pacific Ocean. $J$. Meteor. Soc. Japan, 71, 221-246, https://doi.org/10.2151/ jmsj1965.71.2_221.

_ J. Yokomori, and K. Yoneyama, 2006: A diagnostic study on interactions between atmospheric thermodynamic structure and cumulus convection over the tropical western Pacific Ocean and over the Indochina Peninsula. J. Meteor. Soc. Japan, 84A, 151-169, https://doi.org/10.2151/jmsj.84A.151.

Takemi, T., O. Hirayama, and C. Liu, 2004: Factors responsible for the vertical development of tropical oceanic cumulus convection. Geophys. Res. Lett., 31, L11109, https://doi.org/10. 1029/2004GL020225.

Tam, C. Y., and T. Li, 2006: The origin and dispersion characteristics of the observed tropical summertime synoptic-scale waves over the western Pacific. Mon. Wea. Rev., 134, 16301646, https://doi.org/10.1175/MWR3147.1.

Trenberth, K. E., 1986: An assessment of the impact of transient eddies on the zonal flow during a blocking episode using localized Eliassen-Palm flux diagnostics. J. Atmos. Sci., 43, 2070-2087, https://doi.org/10.1175/1520-0469(1986)043<2070: AAOTIO $>2.0 . \mathrm{CO} ; 2$.

Waugh, D. W., 2005: Impact of potential vorticity intrusions on subtropical upper tropospheric humidity. J. Geophys. Res., 110, D11305, https://doi.org/10.1029/2004JD005664.

Wentz, F. J., K. A. Hilburn, and D. K. Smith, 2012: Remote sensing systems DMSP SSM/I daily environmental suite on 0.25 deg grid, version 7. Remote Sensing Systems, accessed 3 November 2021, www.remss.com/missions/ssmi.

Wheeler, M., and G. N. Kiladis, 1999: Convectively coupled equatorial waves: Analysis of clouds and temperature in the wavenumber-frequency domain. J. Atmos. Sci., 56, 374-399, https://doi.org/10.1175/1520-0469(1999)056<0374:CCEWAO> 2.0.CO;2.

Yokoyama, C., H. Tsuji, and Y. N. Takayabu, 2020: The effects of an upper-tropospheric trough on the heavy rainfall event in July 2018 over Japan. J. Meteor. Soc. Japan, 98, 235-255, https://doi.org/10.2151/jmsj.2020-013.

Zhang, G., Z. Wang, T. J. Dunkerton, M. S. Peng, and G. Magnusdottir, 2016: Extratropical impacts on Atlantic tropical cyclone activity. J. Atmos. Sci., 73, 1401-1418, https://doi.org/ 10.1175/JAS-D-15-0154.1. 